\title{
¿Evaluation of AMSR-E Thin Ice Thickness Algorithm from a Mooring-Based Observation: How Can the Satellite Observe a Sea Ice Field with Nonuniform Thickness Distribution?
}

\author{
HARUHIKO KASHIWASE \\ National Institute of Polar Research, Tachikawa, Japan \\ KAY I. OHSHIMA \\ Institute of Low Temperature Science, and Arctic Research Center, Hokkaido University, Sapporo, Japan \\ YASUSHI FUKAMACHI \\ Institute of Low Temperature Science, and Arctic Research Center, and Global Station for Arctic Research, \\ Hokkaido University, Sapporo, Japan \\ SOHEY NIHASHI \\ National Institute of Technology, Tomakomai College, Tomakomai, Japan
}

TAKESHI TAMURA

National Institute of Polar Research, and SOKENDAI, Graduate University for Advanced Studies, Tachikawa, Japan, and Antarctic Climate and Ecosystems Cooperative Research Centre, University of Tasmania, Hobart, Tasmania, Australia

(Manuscript received 12 December 2018, in final form 15 May 2019)

\begin{abstract}
The quantification of sea ice production in coastal polynyas is a key issue to understand the global climate system. In this study, we directly compared Advanced Microwave Scanning Radiometer-EOS (AMSR-E) data with the sea ice thickness distribution obtained from a mooring observation during the winter of 2003 off Sakhalin in the Sea of Okhotsk to evaluate the algorithm for estimation of sea ice thickness in coastal polynyas. By using thermal ice thickness as a target physical quantity, we found that the obtained relationship between the polarization ratio (PR) and ice thickness can provide an appropriate AMSR-E algorithm to estimate thin ice thickness, irrespective of the uniform or nonuniform ice thickness field. The relationship between the PR value and thermal ice thickness is likewise consistent with the local PR-thickness relationship that is observed at individual ice floes. This is because both the PR value and thermal ice thickness are more sensitive to thinner ice. Furthermore, we evaluated the method for detection of active frazil in a coastal polynya by comparing with the mooring data, and subsequently modified it to classify the coastal polynya into three thin ice types, namely, active frazil, thin solid ice, and mixed ice (mixture of active frazil and thin solid ice). The improved algorithm successfully represents the thermal ice thickness even for a relatively small-scale polynya off Sakhalin and is expected to be useful for better quantification of sea ice production in the global ocean owing to its high versatility.
\end{abstract}

D Denotes content that is immediately available upon publication as open access.

\footnotetext{
Corresponding author: Haruhiko Kashiwase, kashiwase.haruhiko@ nipr.ac.jp
}

\section{Introduction}

Sea ice production in coastal polynyas is a key process in the global climate system. Coastal polynyas are areas of thin ice or open water sustained by divergent ice motion due to wind and ocean currents (Barber and Massom 2007). During the winter, heat loss in coastal polynyas is one or two orders of magnitude greater 
than that in the surrounding thicker sea ice areas (Maykut 1978), and high ice production occurs in such limited areas. A large coastal polynya frequently forms off Ross Ice Shelf and Cape Darnley in the Southern Hemisphere, and in the northwest shelf of Okhotsk Sea in the Northern Hemisphere (Ohshima et al. 2016). Due to the large amount of brine rejection associated with high ice production, dense shelf water (DSW) is subsequently formed in the coastal polynya (Morales Maqueda et al. 2004). DSW formation is thought to be the main source of ventilation of water masses such as the Antarctic Bottom Water (Orsi et al. 1999) and the North Pacific Intermediate Water (Warner et al. 1996; Shcherbina et al. 2003). Furthermore, it has been reported that the Antarctic Bottom Water and the North Pacific Intermediate Water have become warmer and less saline during the last 50 years (Nakanowatari et al. 2007; Purkey and Johnson 2012). These changes suggest weakening of the overturning circulation, which may be associated with the reduction of sea ice production in coastal polynyas.

A typical coastal polynya has a width of $10-100 \mathrm{~km}$ from the coastline and greatly varies from day to day. To track and analyze temporal variations in coastal polynyas, many studies have employed satellite-based passive microwave radiometers that can observe the entire globe almost every day regardless of darkness or cloudiness. The passive microwave radiometer measures vertically and horizontally polarized brightness temperatures $\left(\mathrm{TB}_{\mathrm{V}}\right.$ and $\mathrm{TB}_{\mathrm{H}}$, respectively) at a given frequency. The polarization ratio of microwave radiation [PR value, defined as $\left.\mathrm{PR}=\left(\mathrm{TB}_{\mathrm{V}}-\mathrm{TB}_{\mathrm{H}}\right) /\left(\mathrm{TB}_{\mathrm{V}}+\mathrm{TB}_{\mathrm{H}}\right)\right]$ decreases as sea ice thickens (Steffen and Maslanik 1988; Steffen 1991). Based on this characteristic, an algorithm that classifies sea ice into three types of new ice, young ice, and first-year ice, was developed using brightness temperatures derived from Special Sensor Microwave Imager (SSM/I) with a spatial resolution of $\sim 25 \mathrm{~km}$, and applied to the Bering Sea (Cavalieri 1994) and the Sea of Okhotsk (Martin et al. 1998; Kimura and Wakatsuchi 1999). The amount of sea ice production in coastal polynyas can be obtained by heat budget calculation using thin ice thickness under the assumption that all heat loss from the ocean to the atmosphere is used for the freezing of seawater. Although this assumption implicitly ignores heat from the deeper ocean, it is reasonably valid because the temperature of entire water column is expected to be close to the freezing point $\left(-1.8^{\circ} \mathrm{C}\right)$ over the shallow shelf region $(\leq 200 \mathrm{~m})$, where coastal polynyas frequently form, as observed in the northwest shelf of the Sea of Okhotsk (Shcherbina et al. 2003). The first quantification of sea ice production has been acquired for the Sea of Okhotsk using uniform ice thickness assumptions as $0.05 \mathrm{~m}$ for new ice, $0.2 \mathrm{~m}$ for young ice, and $0.8 \mathrm{~m}$ with $0.16 \mathrm{~m}$ snow for first-year ice (Ohshima et al. 2003).

Thin ice thickness itself is also obtained from satellitebased passive microwave radiometers. Martin et al. (2004) developed an algorithm that estimates sea ice thickness up to $0.2 \mathrm{~m}$ in the Chukchi Sea, from the comparison between the ratio of brightness temperatures at vertically/horizontally polarized 37- $\mathrm{GHz}$ channels of SSM/I, $\mathrm{R}_{37}\left[\mathrm{R}_{37}=\mathrm{TB}_{37 \mathrm{~V}} / \mathrm{TB}_{37 \mathrm{H}}=\right.$ $\left.\left(1+\mathrm{PR}_{37}\right) /\left(1-\mathrm{PR}_{37}\right)\right]$, and thermal ice thickness obtained from Advanced Very High Resolution Radiometer (AVHRR) infrared data (Yu and Rothrock 1996; Drucker et al. 2003). Thermal ice thickness is a hypothetical value of sea ice thickness satisfying the condition that conductive heat flux in sea ice and heat loss from the ocean to the atmosphere are balanced in a certain area under the assumption of uniform sea ice cover. The thermal ice thickness is suitable for heat budget calculation in the estimation of sea ice production, even if the sea ice field is not uniform within a footprint of satellite-based observation. Similar algorithms that use the PR value have also been developed and used for global mapping of sea ice production (Tamura et al. 2007, 2008; Tamura and Ohshima 2011). Additionally, the thin ice thickness algorithm for SSM/I enabled long-term analyses of sea ice production since 1988 (Tamura and Ohshima 2011; Kashiwase et al. 2014; Tamura et al. 2016). After the Advanced Microwave Scanning Radiometer for EOS (AMSR-E) was launched in May 2002, passive microwave radiometer data with a finer spatial resolution of $\sim 12.5 \mathrm{~km}$ have been available for the estimation of thin ice thickness and quantification of sea ice production in coastal polynyas (Martin et al. 2005; Nihashi et al. 2009; Iwamoto et al. 2013, 2014; Nihashi and Ohshima 2015). Similar approaches are also implemented for AMSR2 (Cho et al. 2016; Nihashi et al. 2017) and Soil Moisture and Ocean Salinity (SMOS; Huntemann et al. 2014; TianKunze et al. 2014). Regarding the estimation of sea ice production, finer mapping was recently conducted using clear-sky Moderate Resolution Imaging Spectroradiometer (MODIS) data in the Arctic Ocean (Preußer et al. 2016) and the Southern Ocean (Paul et al. 2015).

The thin sea ice region in coastal polynyas can roughly be divided into two types: active frazil and thin solid ice areas (Nakata et al. 2019). The active frazil area, which is a mixture of frazil/grease ices and open water, appears under turbulent conditions. While thin solid ice area, which is occupied by nilas or thin level ice including consolidated ice from frazil/pancake ices, appears under relatively calm conditions. Nakata et al. (2019) compared multiple satellitebased observations-Advanced Synthetic Aperture Radar 
(ASAR) with a spatial resolution of $\sim 150 \mathrm{~m}$, MODIS with a spatial resolution of $\sim 1 \mathrm{~km}$, and AMSR-E-and showed that the characteristics of microwave radiation at active frazil area greatly differ from those at thin solid ice area. They further developed a high accuracy thin ice thickness algorithm for AMSR-E by incorporating the classification of sea ice into active frazil and thin solid ice.

The relationship between the PR value and sea ice thickness (PR- $h_{i}$ relationship) used for thin ice thickness algorithms is based on the fact that the microwave radiation at the top of the sea ice surface reflects the brine volume within the ice surface layer, which is correlated with physical sea ice thickness (Cox and Weeks 1974; Grenfell and Comiso 1986). This relationship was confirmed by simultaneous observations of sea ice sampling and ship-based passive microwave radiometer in the Cape Bathurst Polynya (Hwang et al. 2007). In principle, the $\mathrm{PR}-h_{i}$ relationship should be valid only for uniform sea ice. However, the satellite-based passive microwave radiometer practically observes many kinds of sea ice floes within a footprint of tens of kilometers size. Previous studies have developed thin ice thickness algorithms using nighttime and clear-sky infrared data derived from AVHRR or MODIS under the assumption of uniform ice thickness distribution in coastal polynyas. In other words, it has not been confirmed whether the thin ice thickness algorithm is applicable under conditions of nonuniform sea ice, daytime measurement, or cloudy/snowfall weathers. To solve these problems, it is indispensable to use in situ comparison data of sea ice thickness with high spatial or temporal resolution that can provide a detailed description of the distribution of sea ice within the footprint.

In this paper, we aim to verify and develop the thin ice thickness algorithm for AMSR-E based on the physical sea ice thickness distribution data obtained from a mooring observation off Sakhalin in the winter of 2003 (Fukamachi et al. 2009). Since the spatial and temporal resolutions of AMSR-E are greatly different from those in the mooring observation, we begin by establishing a method to compare these very different datasets. This study also offers a challenge to elucidate how the satellitebased passive microwave radiometer captures nonuniform conditions of sea ice within the footprint, or more specifically, what characteristics of nonuniform conditions of sea ice are represented by the PR value.

\section{Data and methods}

\section{a. Mooring data}

In situ observation data used in this paper are obtained from a pair of moorings deployed $\sim 18 \mathrm{~km}$ off northern Sakhalin $\left(52^{\circ} 43^{\prime} \mathrm{N}, 143^{\circ} 34^{\prime} \mathrm{E}\right.$, depicted by a

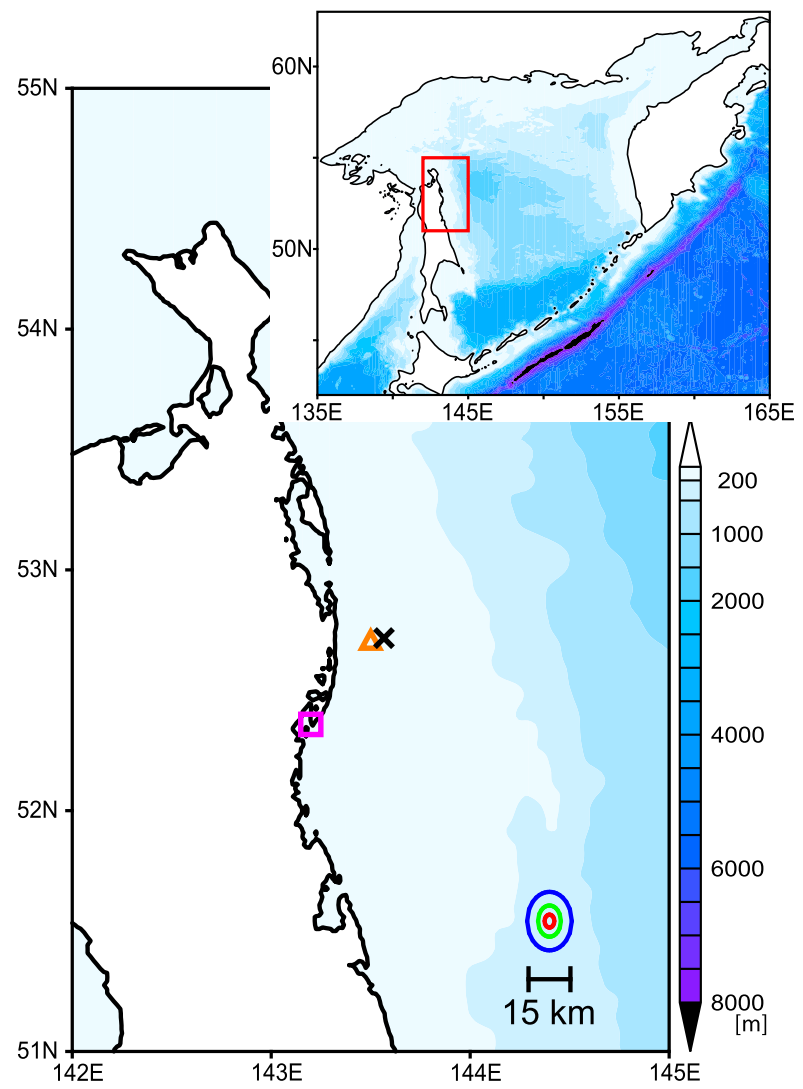

FIG. 1. Locations of the mooring site (black cross), and automatic weather stations near the mooring site (orange triangle) and Chaivo (magenta square). Blue, green, and red oval shapes indicate sizes of the footprint of AMSR-E at 19-, 36-, and 89-GHz channel, respectively. Shadings indicate the bathymetry from the ETOPO1 1 arc-minute global relief model (https://doi.org/10.7289/V5C8276M).

cross symbol in Fig. 1) from 27 December 2002 to 12 June 2003 (Fukamachi et al. 2009). For the observation, one mooring contained the Ice Profiling Sonar (IPS; ASL Environmental Science IPS4 $420 \mathrm{kHz}$ ), and another contained the acoustic Doppler current profiler (ADCP; RD Instruments WH-Sentinel $300 \mathrm{kHz}$ ) and the conductivity-temperature $(\mathrm{CT})$ recorder (Seabird SBE-37). The two moorings were deployed $\sim 120 \mathrm{~m}$ apart to avoid possible acoustic interference, and all three instruments were placed at $24-\mathrm{m}$ depth. In the following descriptions, we treated them as the observation at the same location. The IPS sampling intervals were $1 \mathrm{~s}$ for range data (distance from the instrument to the bottom of sea ice) and $30 \mathrm{~s}$ for pressure and tilt data. The ADCP measured velocities of sea ice drift and water column using the bottom- and water-tracking mode, respectively (Melling et al. 1995). The CT observation data were used for the calculation of sound velocity. Further details are described in Fukamachi et al. (2009). 

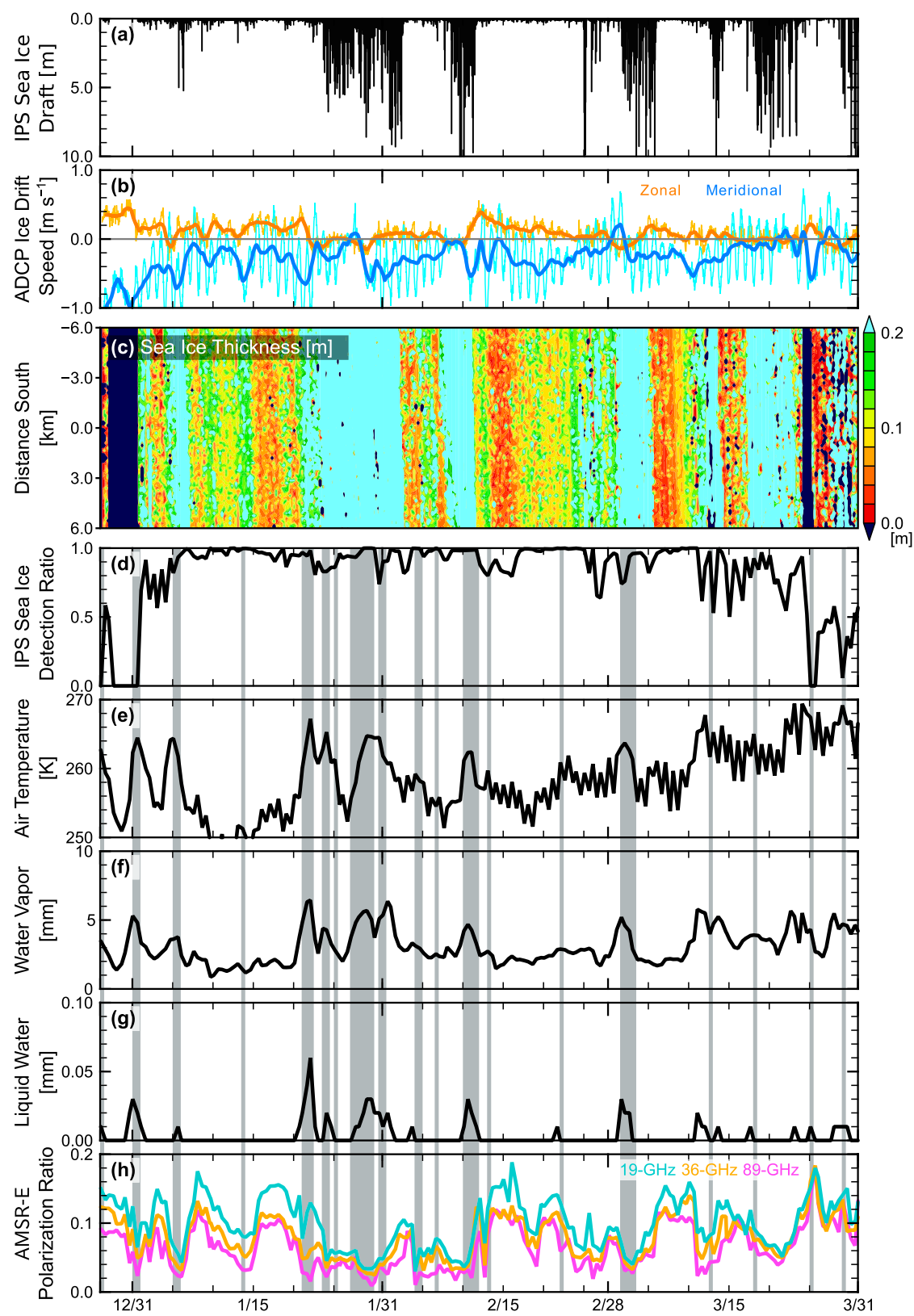

FIG. 2. Time series of physical quantities of sea ice, atmosphere, and AMSR-E at the mooring site. (a) Sea ice draft from IPS, (b) ice drift velocity from ADCP, (c) pseudospatial series of sea ice thickness distribution from the combination of IPS and ADCP data, (d) sea ice detection ratio of IPS, namely, $C_{\text {IPS }}$, (e)-(g) 2-m air temperature, total column water vapor, and total column liquid water from ERA-Interim, and (h) PR values from AMSR-E 19-, 36-, and 89-GHz channels. The gray shading indicates the timings of snowfall observed near the mooring site (triangle in Fig. 1).

Data processing methods of this study essentially follow the previous studies (Melling et al. 1995; Melling and Riedel 1995, 1996; Strass 1998; Fukamachi et al. 2003, 2006, 2009; 2017; Behrendt et al. 2013). The sea ice draft is obtained from the IPS range data, with sea level pressure data observed every hour by the automatic weather station at Chaivo (square symbol in Fig. 1). The time series of sea ice draft is shown in Fig. 2a. The accuracy of IPS draft measurement is estimated to be within $\pm 0.05 \mathrm{~m}$ (Fukamachi et al. 2009). Although the mooring observation lasted until early June, we used only the data up to 31 March to focus on 


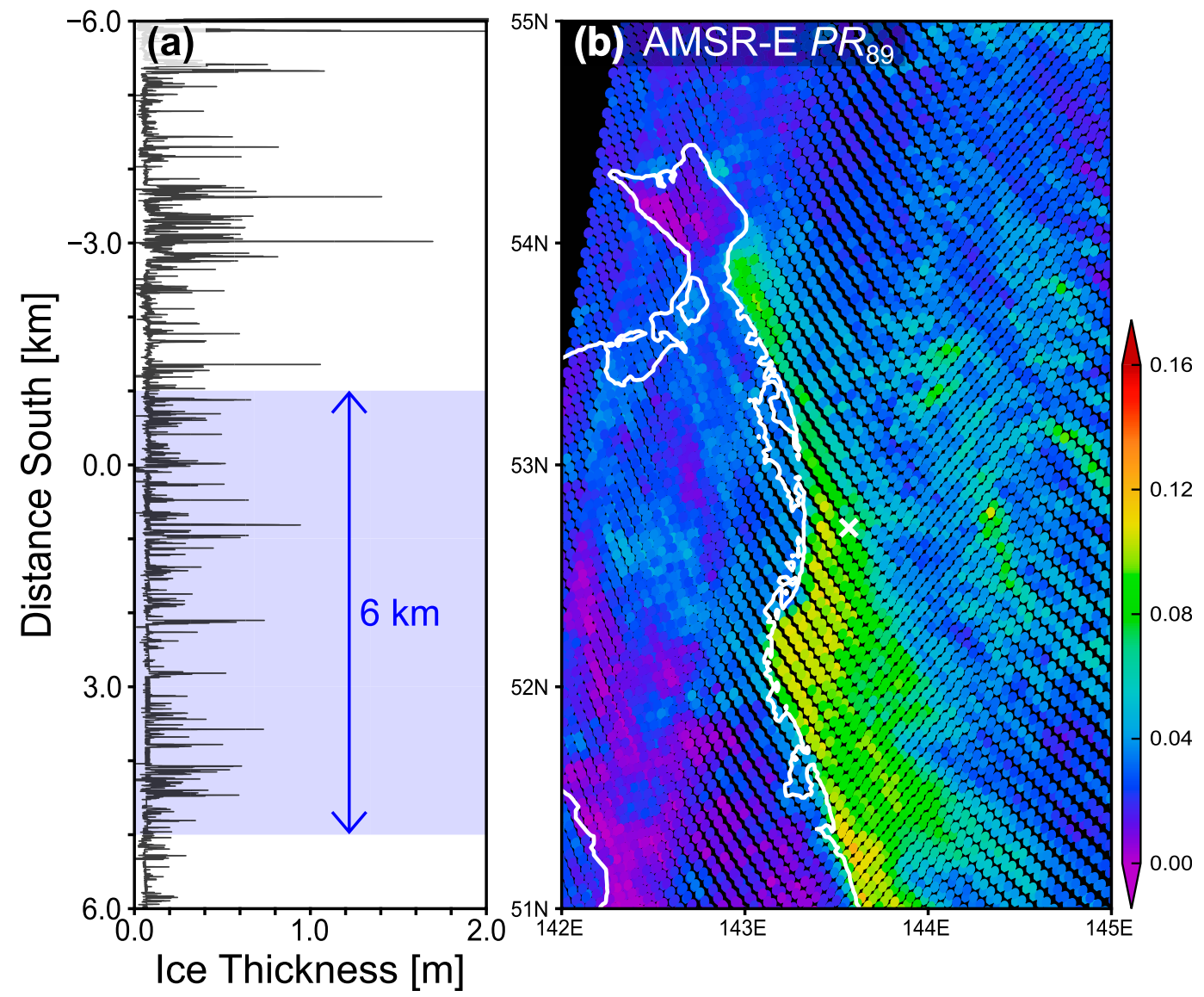

FIG. 3. (a) Meridional distribution of sea ice thickness obtained from the combination of IPS and ADCP observations and (b) spatial distribution of $\mathrm{PR}_{89}$ from AMSR-E near the mooring site (white cross), at 1559 UTC $17 \mathrm{Feb} 2003$, when a coastal polynya appeared. The blue shading in (a) indicates the area (12 001 segments of the ice thickness data) corresponding to the footprint of AMSR-E observation.

the winter season when the formation of coastal polynya occurs.

In this study, we compared the AMSR-E data with detailed sea ice thickness distribution obtained by the mooring observation. Since we focus on thin sea ice, conversion from the draft measured by IPS to the ice thickness was carried out under the assumption of isostasy with fixed values of snow thickness and densities of seawater and sea ice as $0 \mathrm{~m}, 1026.5 \mathrm{~kg} \mathrm{~m}^{-3}$, and $920 \mathrm{~kg} \mathrm{~m}^{-3}$, respectively. To treat the sea ice thickness data at a certain spatial scale, it is necessary to create the pseudospatial series of sea ice thickness by combining the time series of thickness and drift velocity of sea ice at the mooring site. A continuous time series of sea ice velocity is needed for this purpose. The ADCP velocity measurement with a sampling interval at $20 \mathrm{~min}$, however, sometimes exhibits data gaps. Such data gaps were filled by a multilinear regression of ice velocity against near-surface water velocity from the uppermost ADCP bin (5-7 $\mathrm{m}$ deep) and the surface wind measured at
Chaivo weather station, as described in Fukamachi et al. (2009). The continuous time series of ice drift velocity obtained by this method is shown in Fig. 2b. The accuracy of ice drift velocity is less than $0.01 \mathrm{~m} \mathrm{~s}^{-1}$.

Off the east coast of Sakhalin, the southward East Sakhalin Current is dominant (Mizuta et al. 2003), and this has also been confirmed by the ice drift velocity data (Fig. 2b). Hence, in this study, we created a dataset of pseudospatial series of sea ice thickness by using only the southward component of ice drift velocity data. This dataset contains information on ice thickness for every $0.5 \mathrm{~m}$ of sea ice advection to the south (Fig. 2c). If the temporal change in sea ice thickness is negligible, the dataset provides a meridional distribution of sea ice thickness. Figure $3 \mathrm{a}$ is an example of meridional sea ice thickness distribution at the time of AMSR-E observation at 1559 UTC 17 February 2003. For comparison, we used the meridional thickness distribution in the range of $\pm 3 \mathrm{~km}$ centered at the AMSR-E observational latitude, which corresponds to the 12001 segments of sea ice 
thickness, as shown by the blue shading in Fig. 3a. These data are regarded as being representative of sea ice thickness distribution in the AMSR-E footprint, where zonal changes in the sea ice thickness distribution are assumed to be negligible. This pseudospatial series of sea ice thickness data corresponds to the time series of $\pm 4 \mathrm{~h}$ from the observational time when the ice drift velocity is assumed to be constant at $0.2 \mathrm{~m} \mathrm{~s}^{-1}$ to the south.

In the present study, we assume that sea ice concentration at the mooring site is maintained at $100 \%$ during the winter. Since the heat flux at the mooring site is almost always from the ice/ocean to the atmosphere until the end of March (Fukamachi et al. 2009), the freezing of seawater will occur immediately when the open water area is formed by divergent ice motion caused by the wind or ocean currents. However, it should be noted that the IPS cannot detect frazil ice and solid ice with a thickness smaller than the observational accuracy of $\sim 0.05 \mathrm{~m}$. Figure $2 \mathrm{~d}$ shows the time series of the ratio of sea ice detection by IPS measurement $\left(C_{\text {IPS }}\right)$ at the time of AMSR-E observation nearest to the mooring site. Here $C_{\mathrm{IPS}}$ is defined as the ratio of segments where sea ice is detected within 12001 segments of the AMSR-E footprint. When $C_{\mathrm{IPS}}$ is close to $100 \%$, it can be assumed that solid ice is predominant within the footprint. While, when $C_{\text {IPS }}$ is small, it is difficult to distinguish whether the footprint is covered with frazil ice or solid ice thinner than the lower limit of IPS ice detection. In this study, we assume a constant ice thickness of $0.02 \mathrm{~m}$ in the case of no ice detection by IPS, which corresponds to a typical thermal ice thickness of frazil ice (Nakata et al. 2019). This assumption does not affect our results significantly, as we mainly use the case of $C_{\mathrm{IPS}} \geq 95 \%$ (where mean $C_{\text {IPS }}$ exceeds $98 \%$ ). Even if the assumed constant ice thickness for no ice detection is changed to $0-0.04 \mathrm{~m}$, this results in only $\pm 2 \%$ change in thermal ice thickness for the case when $C_{\mathrm{IPS}} \geq 95 \%$.

\section{b. AMSR-E data}

We used the AMSR-E/Aqua L2A global swath spatially resampled brightness temperatures, version 3 (Ashcroft and Wentz 2013) at 19-, 36-, and 89-GHz, derived directly from the Level $1 \mathrm{~A}$ observation without spatial averaging. The AMSR-E observes the area near the mooring site twice in $24 \mathrm{~h}$, in the daytime and nighttime (around 0200 and 1600 UTC, respectively). Footprint sizes of the 19-, 36-, and 89-GHz observations are $16 \mathrm{~km} \times 27 \mathrm{~km}, 8 \mathrm{~km} \times 14 \mathrm{~km}$, and $4 \mathrm{~km} \times$ $6 \mathrm{~km}$, respectively, and depicted by oval shapes in Fig. 1. To compare the AMSR-E observation with sea ice thickness distribution on the same spatial scale, we conducted optimal interpolation for 19 - and $36-\mathrm{GHz}$ data into the $4 \mathrm{~km} \times 6 \mathrm{~km}$ footprint to fit the $89-\mathrm{GHz}$ footprint, using the Backus-Gilbert method (Poe 1990; Hunewinkel et al. 1998).

Generally, satellite-based passive microwave radiometer data contain information on atmospheric radiation as well as microwave radiation at the sea ice surface (Mätzler 1992). The brightness temperature observed by AMSR-E is expressed by the following equation (Wentz 1997),

$$
\mathrm{TB}=\mathrm{TB}_{u}+\tau\left[\bar{E}_{s}+(1-\bar{E}) \mathrm{TB}_{d}\right],
$$

where $\mathrm{TB}_{u}$ and $\mathrm{TB}_{d}$ are upward and downward atmospheric radiations, respectively, and $\tau$ is the transmittance of the atmosphere. The terms $\bar{E}$ and $\bar{T}_{s}$ denote the emissivity and temperature at the sea ice surface averaged over the AMSR-E footprint, respectively. Previous thin ice thickness algorithms have used MODIS or AVHRR at clear-sky and nighttime conditions to derive the PR $-h_{i}$ relationship. In these cases, the influence of atmospheric radiation can be regarded as a small constant. Meanwhile, the present study uses the mooring data obtained regardless of weather conditions, which provides bias-free data while needs to consider the influence of atmospheric radiation on AMSR-E data for comparison.

Here we calculate $\mathrm{TB}_{u}, \mathrm{~TB}_{d}$, and $\tau$ using a simple radiative transfer model (Wentz and Meissner 2000) for every timing of the AMSR-E observation, and correct them to adjust the reference condition of 2-m air temperature of $-10^{\circ} \mathrm{C}$ and total column water vapor of $0 \mathrm{~mm}$. We used the atmospheric data from the ECMWF interim reanalysis (ERA-Interim) dataset with a 6-h interval and a spatial resolution of $0.75^{\circ} \times 0.75^{\circ}$ (Dee et al. 2011). Figures $2 \mathrm{e}$ and $2 \mathrm{f}$ indicate the time series of $2-\mathrm{m}$ air temperature and total column water vapor linearly interpolated at the AMSR-E footprint nearest to the mooring site. The $\bar{T}_{s}$ was obtained from the heat budget calculation using the sea ice thickness distribution and ERA-Interim data. In this paper, heat budget calculation was conducted in a manner similar to Ohshima et al. (2003), and detailed procedures will be described later in this paper. The $\bar{E}$ was obtained using $\bar{T}_{s}, \mathrm{~TB}_{u}$, $\mathrm{TB}_{d}$, and $\tau$, from the transformation of Eq. (1), as follows (Mathew et al. 2009),

$$
\bar{E}=\frac{\mathrm{TB}-\mathrm{TB}(\bar{E}=0)}{\operatorname{TB}(\bar{E}=1)-\operatorname{TB}(\bar{E}=0)} .
$$

Although the exact atmospheric correction should incorporate the cloud liquid water (Fig. 2g), we omit this because cloud liquid water is poorly represented in current numerical weather prediction models (Andersen et al. 2006; Ivanova et al.2015). Also, we used the automatic 
weather station data near the mooring site (triangle in Fig. 1) to judge the snowfall condition. Snowfall information obtained every half day is indicated by gray shadings in Fig. 2. When snowfall is observed at the time close to the AMSR-E observation, we regard that the sample is obtained under the snowfall condition. Microwave radiation can be strongly affected by snow at the sea ice surface under such conditions. Furthermore, the timing of snowfall corresponds well to that of a relatively large cloud liquid water (Fig. 2g). The PR values after the atmospheric correction are shown in Fig. 2h. By this atmospheric correction, PR values have increased by about $2 \%$ for 19 - and $36-\mathrm{GHz}$ channels, and by about $10 \%$ for the $89-\mathrm{GHz}$ channel.

\section{c. Direct comparison between AMSR-E data and ice thickness distribution within the footprint}

Here we show the case at 1559 UTC 17 February 2003, when a coastal polynya formed around the mooring site, as indicated by the sea ice thickness distribution in the AMSR-E footprint (see Fig. 3a). In accordance with polynya formation, the PR exhibits a relatively high value around the mooring site (Fig. 3b). Previous thin ice thickness algorithms implicitly assume that coastal polynyas have relatively uniform ice thickness distributions (Tamura et al. 2007; Nihashi et al. 2009; Iwamoto et al. 2013). However, the mooring observation indicates that sea ice with a thickness exceeding $1 \mathrm{~m}$ frequently appears even in the coastal polynya. If the $\mathrm{PR}-h_{i}$ relationship can be expressed by a linear function, even for the nonuniform sea ice case, the relationship between the averages of physical ice thickness and PR value should be the same as that of the uniform ice case. In reality, the PR- $h_{i}$ relationship is more sensitive for thinner sea ice, as it is approximated by an exponential function in several studies (Martin et al. 2004, 2005; Iwamoto et al. 2013, 2014; Nihashi and Ohshima 2015; Nihashi et al. 2017; Nakata et al. 2019). Thus, the PR value tends to be affected more by thinner ice under conditions of nonuniform sea ice within the footprint. Therefore, it is important to investigate whether the thin ice thickness algorithm derived from the $\mathrm{PR}-h_{i}$ relationship is applicable under conditions of nonuniform sea ice.

To evaluate the thin ice thickness algorithm for nonuniform sea ice cover, we compared AMSR-E data with sea ice thickness distribution obtained from the mooring observation in two ways. One way is to extract the "local" PR- $h_{i}$ relationship, which can best explain the observed $\mathrm{PR}$ value in terms of ice thickness distribution within the AMSR-E footprint. If the local PR- $h_{i}$ relationship shown by the in situ observation is valid for small segments of the nonuniform sea ice cover, the PR value observed at a certain AMSR-E footprint should agree with the average of $\mathrm{PR}$ values corresponding to the physical ice thicknesses of all the segments within that AMSR-E footprint. Based on this concept, the local relationship can be obtained by identifying the PR- $h_{i}$ relationship that best fits the PR value observed by AMSR-E $\left(\mathrm{PR}_{\mathrm{OBS}}\right)$ and the $\mathrm{PR}$ value predicted from physical ice thickness distribution using that relationship $\left(\mathrm{PR}_{\mathrm{PRE}}\right)$. The other way is to calculate the thermal ice thickness of the nonuniform sea ice cover and compare it with $\mathrm{PR}_{\mathrm{OBS}}$. Then, we can obtain the "bulk" relationship as previously done in the development of thin ice thickness algorithms. In previous studies, thin ice thickness algorithm estimates the thermal ice thickness and provides a useful input for the quantification of the heat budget and sea ice production in coastal polynyas (Iwamoto et al. 2014; Fukamachi et al. 2017). We also compared thermal ice thickness with the AMSR-E PR value in a method similar to previous studies, but independent of observational timing and weather conditions, which is the advantage of this study. The overall procedure is shown as a flowchart in Fig. 4, while the procedure will be described in more detail in section 3.

Here, we describe the specific procedure to obtain the thermal ice thickness from the heat budget calculation. For atmospheric input data, we used the air temperature and dewpoint temperature at $2 \mathrm{~m}$, wind speed at $10 \mathrm{~m}$, sea level pressure, and total cloud cover from ERA-Interim. Total heat loss from the ice surface (FI) and conductive heat flux in ice (FC) are expressed by the following equations,

$$
\begin{aligned}
& \mathrm{FI}=-(1-\alpha) \mathrm{SW}+\mathrm{LN}+\mathrm{SE}+\mathrm{LA}, \\
& \mathrm{FC}=k_{i} \frac{\left(T_{b}-T_{s}\right)}{h_{i}},
\end{aligned}
$$

where $\alpha$ is the albedo of sea ice, SW is shortwave radiation, $\mathrm{LN}$ is net longwave radiation, $\mathrm{SE}$ is sensible heat flux, LA is latent heat flux, and $k_{i}=2.04 \mathrm{~W} \mathrm{~m}^{-1} \mathrm{~K}^{-1}$ is the thermal conductivity of sea ice. Here $T_{s}$ and $T_{b}$ are the surface and bottom temperatures of sea ice, respectively; $T_{b}$ is assumed to be at the freezing point $\left(-1.8^{\circ} \mathrm{C}\right)$. Albedos for new ice $\left(h_{i} \leq 0.1 \mathrm{~m}\right)$, young ice $\left(0.1 \mathrm{~m}<h_{i} \leq\right.$ $0.2 \mathrm{~m})$, and first-year ice $\left(h_{i}>0.2 \mathrm{~m}\right)$ are set to $0.27,0.36$, and 0.7, respectively (Maykut 1986; Allison et al. 1993; Toyota et al. 1999). We used empirical formulas (Kim and Kimura 1995) for the calculation of SW and LN, and bulk formulas (Kondo 1975) for the calculation of SE and LA. For the calculation of LN, SE, and FC, the ice surface temperature $T_{s}$ needs to be determined.

In this paper, we calculated $T_{s_{m}}$ that satisfies $\mathrm{FI}_{m}=\mathrm{FC}_{m}$, where subscript $m$ indicates a segment of pseudospatial 


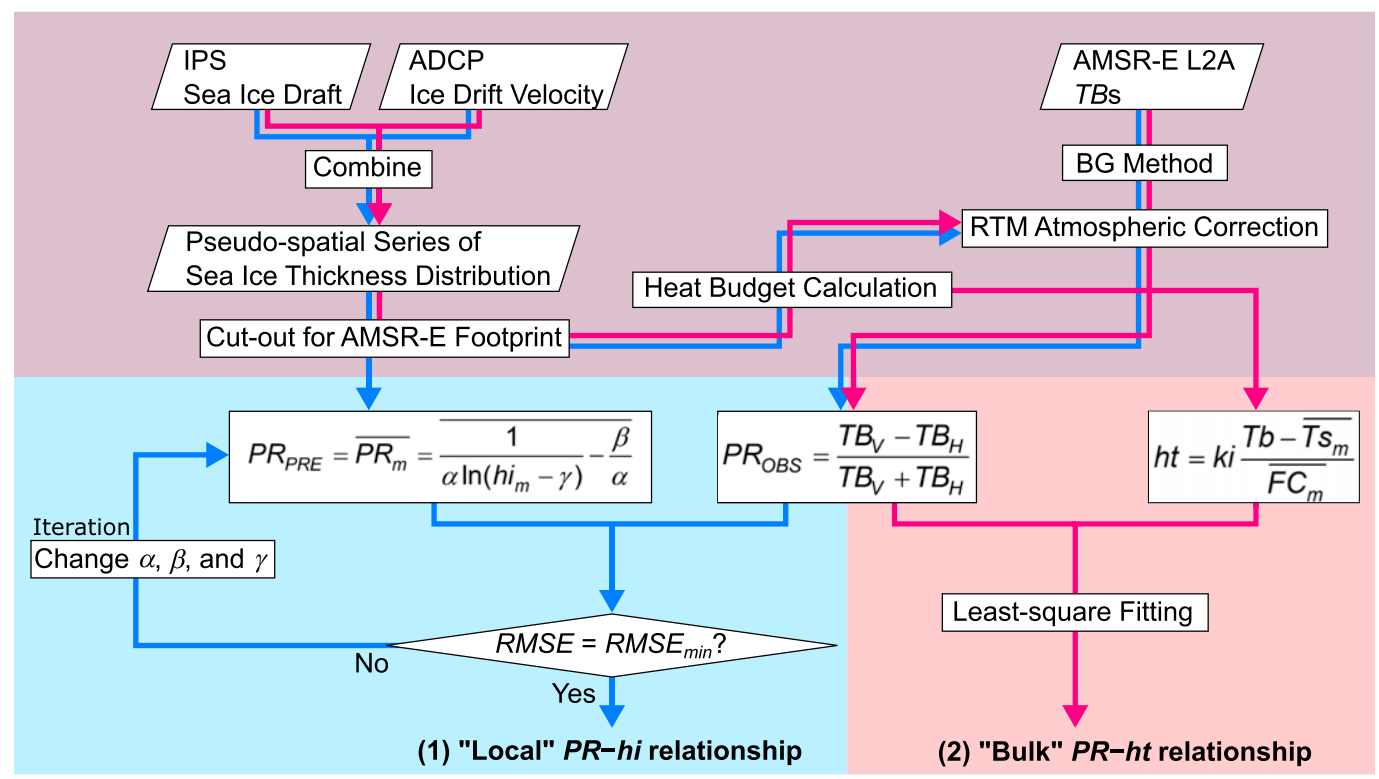

FIG. 4. Flowchart of the procedure for deriving the thin ice thickness algorithm. Blue and red shaded areas correspond to the procedure to extract the local and bulk PR $h_{i}$ relationships, respectively. Refer to the text for abbreviations used in the chart.

series of sea ice thickness distribution. Then, we averaged them over the AMSR-E footprint (corresponding to the 12001 segments of sea ice thickness distribution), and calculated the thermal ice thickness $h_{t}$ by the following equation,

$$
h_{t}=k_{i} \frac{T_{b}-\overline{T_{s_{m}}}}{\overline{\mathrm{FC}_{m}}} .
$$

Hereinafter, we refer to the thermal ice thickness in the AMSR-E footprint calculated from the IPS ice thickness distribution data as the IPS thermal ice thickness.

Since the heat flux over sea ice has the characteristic of increasing nonlinearly as the thickness of sea ice decreases, large heat loss occurs in thin ice portions of the nonuniform sea ice cover. Although thermal ice thickness coincides with physical ice thickness under the uniform sea ice condition, it is smaller than the average of physical ice thickness $\left(\bar{h}_{i_{m}}\right)$ as the standard deviation of physical ice thickness $\left(\mathrm{SD}_{h_{i}}\right)$ is larger. Figure $5 \mathrm{a}$ is a scatterplot of averaged physical and thermal ice thicknesses calculated in the AMSR-E footprint, where the color of symbol shows the range of standard deviation of physical ice thickness. For the range of the averaged physical ice thickness of $\leq 0.4 \mathrm{~m}$, the thermal ice thickness becomes smaller by about $33 \%$ on average. Figure $5 b$ shows the scatterplot of standard deviation of physical ice thickness, $\mathrm{SD}_{h_{i}}$, versus difference between the averages of physical and thermal ice thickness, $\bar{h}_{i_{m}}-h_{t}$. The least squares fitting gives $\bar{h}_{i_{m}}-h_{t}=0.19 \mathrm{SD}_{h_{i}}^{2}+0.15 \mathrm{SD}_{h_{i}}$ $\left(n=133 ; R^{2}=0.97 ; p\right.$ value $\left.<0.01\right)$. Although the case of daytime (red symbols) shows slightly larger variance, probably due to the uncertainty of shortwave radiation, it exhibits no significant difference from the case of nighttime (blue symbols) as confirmed by Welch's $t$ test $(\nu=107 ; t$ value $=0.51 ; p$ value $>0.5)$. This suggests that thermal ice thickness depends only on the distribution of physical sea ice thickness, regardless of observational timing in daytime or nighttime.

\section{Results}

\section{a. $\mathrm{PR}-h_{i}$ relationship under nonuniform sea ice conditions}

First, we consider the local relationship between PR value and physical sea ice thickness, shown by the blue segment of the flowchart in Fig. 4. Assuming that a common exponential relationship $\left\{h_{i_{m}}=\exp \left[1 /\left(\alpha \mathrm{PR}_{m}+\beta\right)\right]+\gamma\right\}$ is established in any segment of sea ice thickness data, we are able to predict the PR value that will be observed by AMSR-E as the average of PR values obtained from the 12001 segments of sea ice thickness data within the AMSR-E footprint,

$$
\mathrm{PR}_{\mathrm{PRE}}=\overline{\mathrm{PR}_{m}}=\overline{\frac{1}{\alpha \ln \left(h_{i_{m}}-\gamma\right)}-\frac{\beta}{\alpha}} .
$$

If the assumption on the $\mathrm{PR}-h_{i}$ relationship and values of $\alpha, \beta$, and $\gamma$, is appropriate, $\mathrm{PR}_{\mathrm{PRE}}$ should be matched 

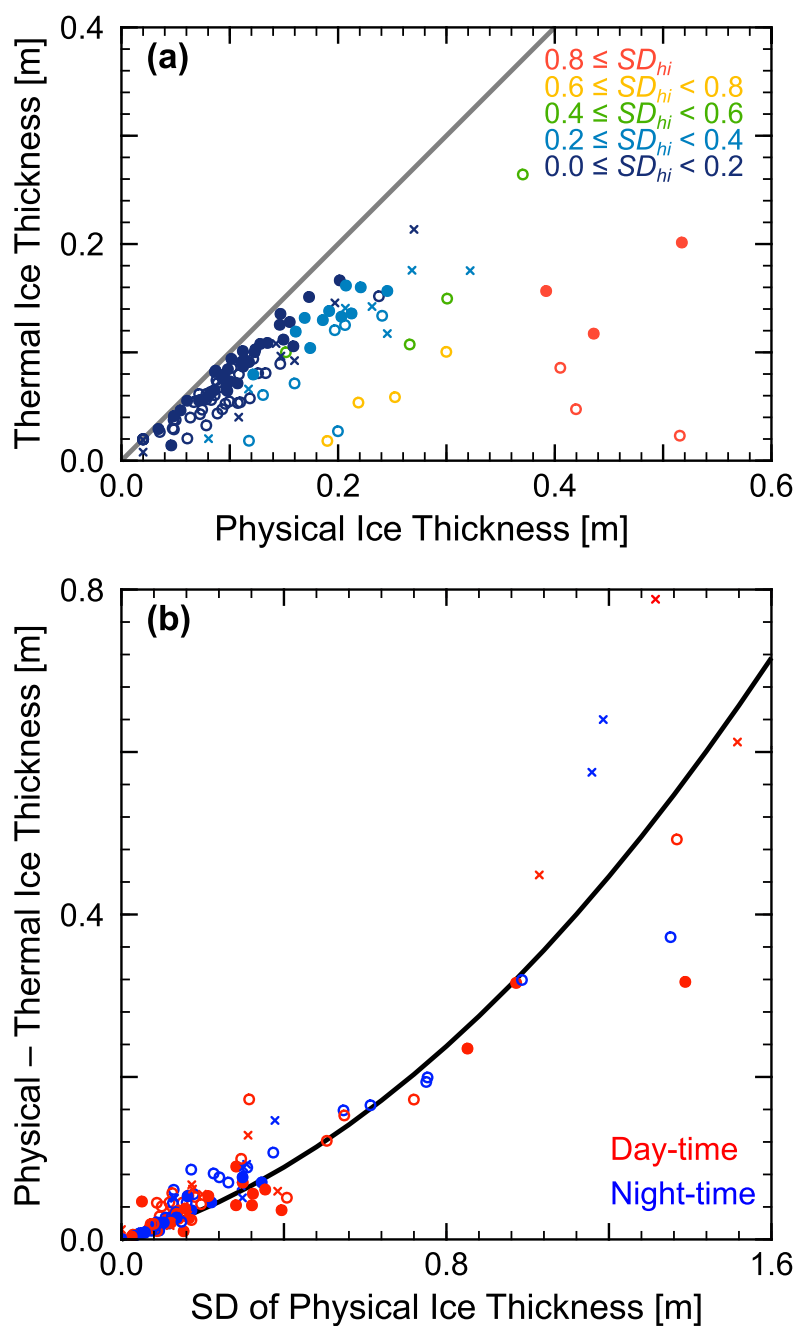

FIG. 5. Comparison of physical sea ice thickness distribution with thermal ice thickness. (a) Scatterplot of the averaged physical and thermal ice thicknesses, where the color of the symbol shows the range of standard deviation of physical ice thickness. (b) Scatterplot of standard deviation of physical ice thickness vs difference between the averages of physical and thermal ice thickness for AMSR-E footprints. The cases of $C_{\text {IPS }} \geq 95 \%$ and $C_{\text {IPS }}<95 \%$ are shown by filled and open circles, respectively, and the case of the snowfall condition is shown by crosses. Red and blue colors in (b) indicate daytime and nighttime data, respectively. The black solid curve is obtained by least squares fitting.

with $\mathrm{PR}_{\mathrm{OBS}}$ in any case. In this paper, we calculated $\mathrm{PR}_{\mathrm{PRE}}$ for 61 cases with $C_{\mathrm{IPS}} \geq 95 \%$ and no snowfall condition, by changing $\alpha, \beta$, and $\gamma$, and then searched for the best combination of these parameters that minimizes the root-mean-square difference between $P_{P R E}$ and $\mathrm{PR}_{\mathrm{OBS}}$, where the tie point of $\mathrm{PR}$ value at the open water is fixed as $0.31,0.24$, and 0.17 for $19-, 36-$, and 89-GHz channels, respectively (Markus and Cavalieri 2009). This search provides the following local relationship for 19-, 36-, and 89-GHz channels,

$$
\begin{aligned}
& h_{i_{19}}=\exp \left(\frac{1}{86 \mathrm{PR}_{19}-0.9}\right)-1.04, \\
& h_{i_{36}}=\exp \left(\frac{1}{103 \mathrm{PR}_{36}-0.8}\right)-1.04, \text { and } \\
& h_{i_{89}}=\exp \left(\frac{1}{99 \mathrm{PR}_{89}}\right)-1.06
\end{aligned}
$$

Figure 6 shows scatterplots of PR values observed by AMSR-E and predicted from Eqs. (7)-(9). The color of the symbol shows the range of $C_{\text {IPS. }}$. In the case of $C_{\mathrm{IPS}} \geq 95 \%$ (filled circles), the bias of $\mathrm{PR}_{\mathrm{PRE}}$ against $\mathrm{PR}_{\mathrm{OBS}}$ is close to zero for all channels, while in the case of $C_{\mathrm{IPS}}<95 \%$ (open circles), $\mathrm{PR}_{\mathrm{PRE}}$ is significantly biased toward larger values. This suggests the presence of frazil ice having a different $\mathrm{PR}-h_{i}$ relationship from the thin solid ice (Nakata et al. 2019) in the case of lower $C_{\text {IPS, }}$ which will be discussed later in this paper.

Next, we consider the bulk relationship between PR value and nonuniform sea ice thickness distribution, shown by the red segment of the flowchart in Fig. 4. Within a footprint of AMSR-E, ice thickness distribution deviates from uniformity to some extent even in the coastal polynya (Fig. 3), and thus we examine which features of nonuniform sea ice distribution are reflected in PR values observed by AMSR-E. Here we take notice of the concept of thermal ice thickness that has been used in previous thin ice thickness algorithms. As described above, both the PR value observed by AMSR-E and thermal ice thickness are more significantly affected by thinner sea ice portions within an AMSR-E footprint. Therefore, the concept of thermal ice thickness is expected to be convenient as a bulk method for handling the nonuniform sea ice cover. Figure 7 shows scatterplots of the PR value observed by AMSR-E and IPS thermal ice thickness. Exponential curves for the bulk relationships (black solid curves in Fig. 7) can be obtained from the least squares method for the case of $C_{\text {IPS }} \geq 95 \%$ and $h_{t} \leq 0.4 \mathrm{~m}$, and are expressed as follows,

$$
\begin{aligned}
& h_{t_{19}}=\exp \left(\frac{1}{70 \mathrm{PR}_{19}}\right)-1.05, \\
& h_{t_{36}}=\exp \left(\frac{1}{84 \mathrm{PR}_{36}}\right)-1.05, \text { and } \\
& h_{t_{89}}=\exp \left(\frac{1}{98 \mathrm{PR}_{89}}\right)-1.06,
\end{aligned}
$$

where the tie points of the PR value at open water are fixed at the same values in the local relationships. Surprisingly, we found that the bulk relationship obtained 

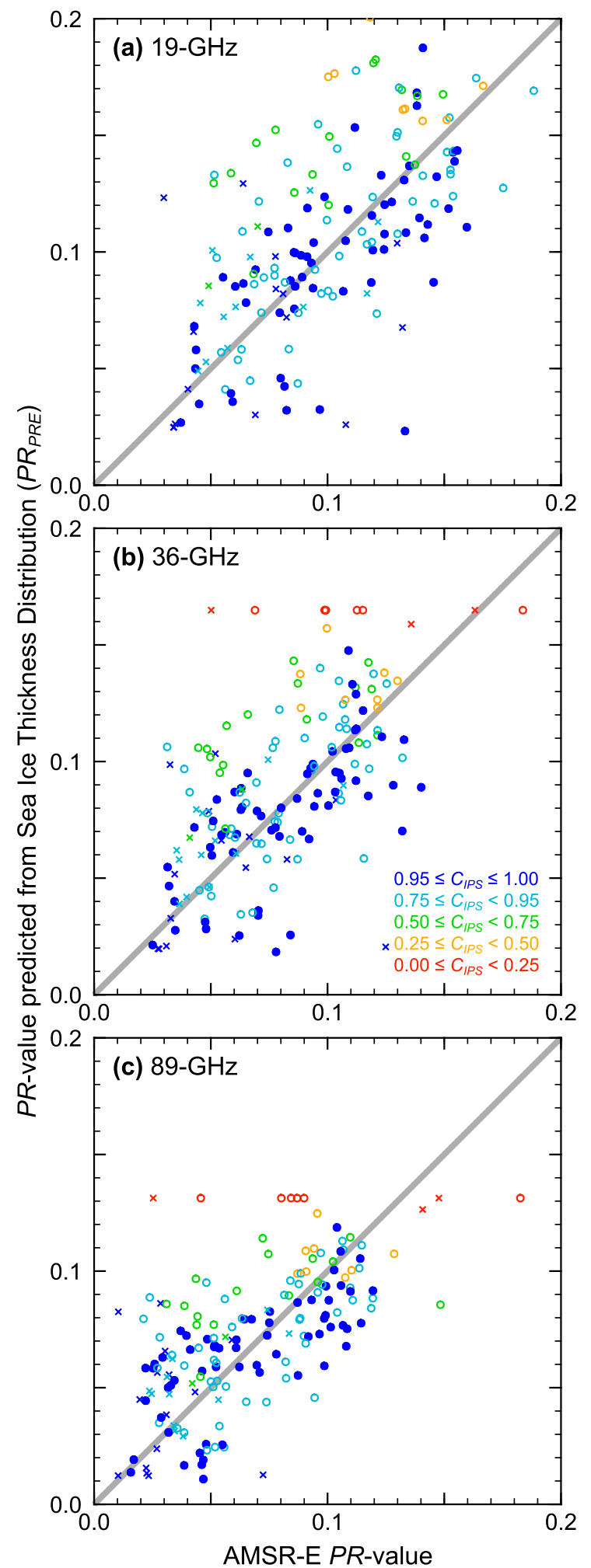

FIG. 6. Scatterplots of PR values observed by AMSR-E (PR $\left.{ }_{\mathrm{OBS}}\right)$ and predicted from the physical ice thickness distribution $\left(\mathrm{PR}_{\mathrm{PRE}}\right)$. Results of (a) 19-, (b) 36-, and (c) 89-GHz channel data are shown. The gray solid line is the relational expression between the PR by thermal ice thickness matches well with the local relationship (gray solid lines in Figs. 6 and 7) for all channels. In the case of the $36-\mathrm{GHz}$ channel, the in situ observation by Hwang et al. (2007), where $R_{37}$ is converted to $\mathrm{R}_{36}$ in accordance with Martin et al. (2005) and then converted to $\mathrm{PR}_{36}$, is also consistent with the relationship (diamond symbols in Fig. 7b). A good agreement between local and bulk relationships suggests that the thermal ice thickness, which can be estimated from the PR value, is suitable as a representative thickness of the nonuniform sea ice cover.

\section{b. Evaluation and improvement of the algorithm for thin ice type classification}

Figure 8 shows bulk relationships between PR value and thermal ice thickness for AMSR-E 36- and 89-GHz channels obtained by this study and previous studies. The results of this study (black solid curves) are very close to those obtained by Nihashi and Ohshima (2015) and Nakata et al. (2019) (green and purple solid curves, respectively), while, significantly different from those obtained by Martin et al. (2005) and Iwamoto et al. (2013) (magenta and orange solid curves, respectively). It has been shown that the active frazil with a certain PR value is considerably thinner than the thin solid ice with the same PR value (the bulk relationship for active frazil is indicated by purple dashed curve in Fig. 8a), and thus the discrepancies in the $\mathrm{PR}-h_{i}$ relationships among previous algorithms can be explained by the difference in presence of active frazil (Nakata et al. 2019). In previous studies, the $\mathrm{PR}-h_{i}$ relationship was obtained without considering the thin ice type. Thus, previous algorithms are expected to over or underestimate the thermal ice thickness due to fluctuations in the active frazil controlled by weather conditions. This is the main reason why a universal thin ice thickness algorithm considering the thin ice type is required for better quantification of polynya variability and associated sea ice production.

An AMSR-E algorithm for detection of active frazil in Antarctic coastal polynyas was developed using $\mathrm{PR}_{36}$ and $\mathrm{GR}_{8936 \mathrm{~V}}$ (Nakata et al. 2019), where $\mathrm{GR}_{8936 \mathrm{~V}}$ denotes the gradient ratio of brightness temperature at vertically polarized $36-$ and $89-\mathrm{GHz}$ channels and is defined as $\left(\mathrm{TB}_{89 \mathrm{~V}}-\mathrm{TB}_{36 \mathrm{~V}}\right) /\left(\mathrm{TB}_{89 \mathrm{~V}}+\mathrm{TB}_{36 \mathrm{~V}}\right)$. When the value

value and ice thickness such that $\mathrm{PR}_{\mathrm{PRE}}$ and $\mathrm{PR}_{\mathrm{OBS}}$ in the case of $C_{\text {IPS }} \geq 95 \%$ (blue filled circles) are best matched. The case of $C_{\mathrm{IPS}}<95 \%$ is depicted by open circles with their color indicating the range of $C_{\text {IPS }}$, and the case of the snowfall condition is shown by crosses. 

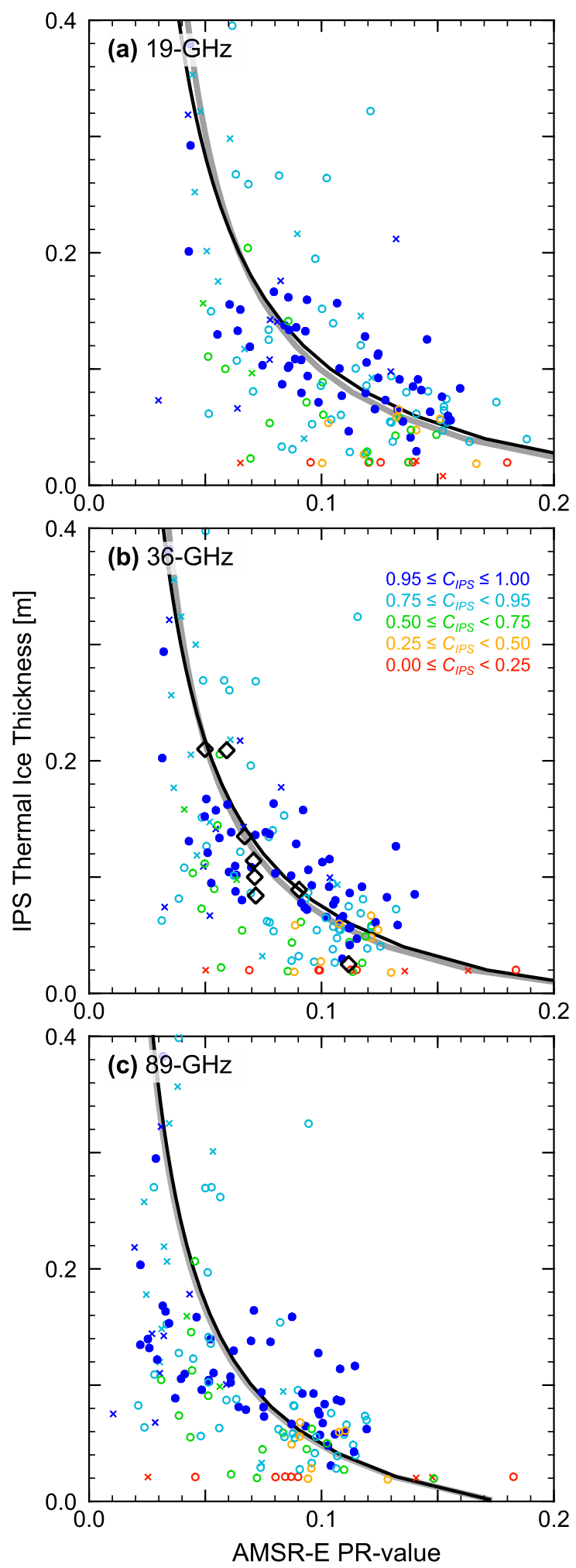

FIG. 7. Scatterplots of PR value observed by AMSR-E (PR $\left.{ }_{\mathrm{OBS}}\right)$ and IPS thermal ice thickness $h_{t}$. Symbols and their coloring are the same as those in Fig. 6, and the diamonds indicate the results of in situ observation by Hwang et al. (2007). The black solid curve is the of $\mathrm{PR}_{36}$ is larger than 0.05 and the discriminant function of $G_{f}\left(\mathrm{PR}_{36}, \mathrm{GR}_{8936 \mathrm{~V}}\right)=-193 \mathrm{PR}_{36}+1002 \mathrm{GR}_{8936 \mathrm{~V}}-$ 0.7 is larger than 0 , that pixel is classified as active frazil. This method is effective for Antarctic coastal polynyas, where the active frazil extends to a relatively large area. Meanwhile, in the small-scale coastal polynya off Sakhalin, active frazil area is usually mixed with thin solid ice area at the spatial scale of the AMSR-E footprint, as shown in the case of lower $C_{\mathrm{IPS}}$. A scatterplot of $\mathrm{PR}_{36}$ and $\mathrm{GR}_{8936 \mathrm{~V}}$ at the mooring site (Fig. 9a) shows that such mixed areas of active frazil and thin solid ice (hereinafter, defined as mixed ice) are classified as thin solid ice in this method. However, since the mixed ice is obviously thinner than the thin solid ice at the same PR value (Fig. 7), this classification method results in overestimation of thermal ice thickness for small-scale coastal polynyas.

We classify the coastal polynya area into three ice types-active frazil, thin solid ice, and mixed icethrough modification of the algorithm of Nakata et al. (2019) by employing $\mathrm{GR}_{8919 \mathrm{~V}}$. Figure $9 \mathrm{~b}$ shows the scatterplot of $\mathrm{PR}_{36}$ and $\mathrm{GR}_{8919 \mathrm{~V}}$ at the mooring site. Since $\mathrm{GR}_{8919 \mathrm{~V}}$ is highly sensitive to the type of sea ice as shown by the ice-tank experiment (Shokr et al. 2009), active frazil/mixed ice and thin solid ice (lower and higher $C_{\text {IPS }}$ cases, respectively) can be separated well by using $\mathrm{PR}_{36}$ and $\mathrm{GR}_{8919 \mathrm{~V}}$. We carried out linear discriminant analysis and defined the discriminant function of $G_{s}\left(\mathrm{PR}_{36}, \mathrm{GR}_{8919 \mathrm{~V}}\right)=-95 \mathrm{PR}_{36}+844 \mathrm{GR}_{8919 \mathrm{~V}}-11.6$ as the line that best discriminates between cases of $C_{\mathrm{IPS}} \geq 95 \%$ and $C_{\mathrm{IPS}}<25 \%$ (representatives of thin solid ice and mixed ice, respectively). The specific classification method is as follows. First, when $\mathrm{PR}_{36}>0.05$ and $G_{s}\left(\mathrm{PR}_{36}, \mathrm{GR}_{8919 \mathrm{~V}}\right)>0.0$, the pixel is classified as mixed ice or active frazil, and the other case is classified as thin solid ice. Second, discrimination between active frazil and mixed ice is carried out by using $\mathrm{PR}_{36}$ and $\mathrm{GR}_{8936 \mathrm{~V}}$, following the protocol in Nakata et al. (2019). Thereby, we can classify the polynya area into three ice types. Table 1 summarizes the result of this classification of thin ice type for each range of $C_{\text {IPS. Although the }}$ number of samples for the case of lower $C_{\mathrm{IPS}}$ is not large, and $C_{\text {IPS }}$ does not necessarily mean the fraction of thin sold ice within the AMSR-E footprint, the classification adequately depends on the value of $C_{\mathrm{IPS}}$. Larger $C_{\text {IPS }}$ corresponds well to a higher percentage of

bulk PR $-h_{t}$ relationship for the case of $C_{\mathrm{IPS}} \geq 95 \%$, and the gray solid curve is the local $\mathrm{PR}-h_{i}$ relationship, corresponding to the gray solid line in Fig. 6. 

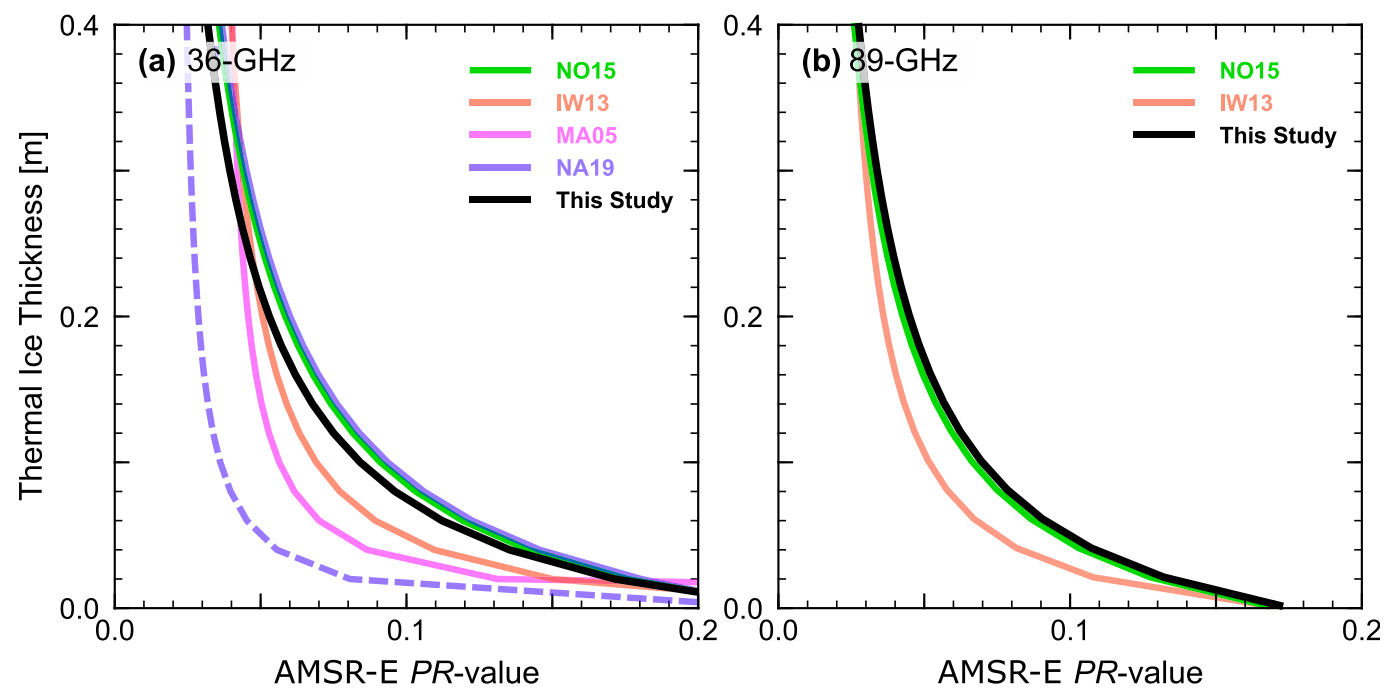

FIG. 8. Comparison of thin ice thickness algorithms for AMSR-E. Bulk relationship between PR value and thermal ice thickness for (a) 36- and (b) 89-GHz channels, obtained by this study is shown by black, and those of previous studies are shown by green (Nihashi and Ohshima 2015: NO15), orange (Iwamoto et al. 2013: IW13), and magenta (Martin et al. 2005: MA05). Purple solid and dashed curves (Nakata et al. 2019: NA19) indicate bulk relationships for thin solid ice and active frazil, respectively.

thin solid ice. However, the rate of misclassifying thin solid ice (case of high $C_{\text {IPS }}$ ) as active frazil is significantly larger in snowfall conditions (cross symbols in Fig. 9). This may be due to the influence of snow cover on microwave radiation at the sea ice surface. Therefore, the present method cannot be applied to the snowfall condition. With this exception, the classification method using $\mathrm{PR}_{36}, \mathrm{GR}_{8936 \mathrm{~V}}$, and $\mathrm{GR}_{8919 \mathrm{~V}}$ is considered to be effective.

\section{c. Application of the improved thin ice thickness algorithm to the Sakhalin coastal polynya}

We improved the thin ice thickness algorithm, providing higher versatility compared to that in previous studies, by the direct comparison between AMSR-E and mooring-based sea ice data. In this subsection, we apply the algorithm to the Sakhalin coastal polynya during the winter of 2003. Figure 10a shows the time series of
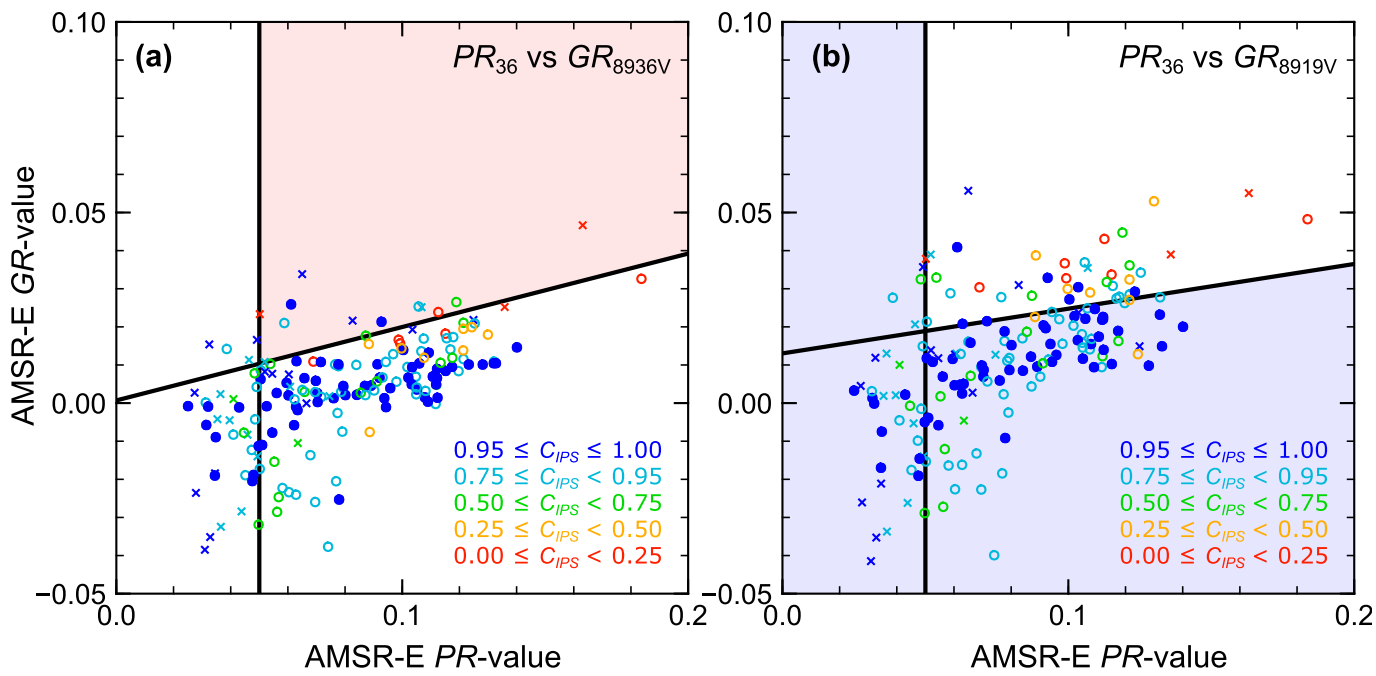

FIG. 9. Results of thin ice type classification from AMSR-E data at the mooring site. Scatterplots of (a) $P_{36} \mathrm{vs}$ $\mathrm{GR}_{8936 \mathrm{~V}}$ and (b) $\mathrm{PR}_{36}$ vs $\mathrm{GR}_{8919 \mathrm{~V}}$ are shown. Symbols and coloring are the same as those in Fig. 6. Red and blue shaded areas are classified as active frazil and thin solid ice, respectively. The discriminant function for active frazil in (a) is obtained by Nakata et al. (2019), and that for thin solid ice in (b) is obtained by the linear discriminant analysis for best discrimination of the cases of $C_{\text {IPS }} \geq 95 \%$ (blue filled circles) and $C_{\text {IPS }}<25 \%$ (red open circles). 
TABLE 1. Ratio of three ice types for each range of $C_{\text {IPS }}$ from the ice type classification by the algorithm.

\begin{tabular}{lccc}
\hline \hline \multicolumn{4}{c}{ Number of samples (ratio of classification) } \\
\hline & Thin solid ice & Mixed ice & Active frazil \\
\hline $0.95 \leq C_{\text {IPS }} \leq 1.00$ & $54(89 \%)$ & $5(8 \%)$ & $2(3 \%)$ \\
$0.75 \leq C_{\text {IPS }}<0.95$ & $41(82 \%)$ & $7(14 \%)$ & $2(4 \%)$ \\
$0.50 \leq C_{\text {IPS }}<0.75$ & $11(69 \%)$ & $3(19 \%)$ & $2(12 \%)$ \\
$0.25 \leq C_{\text {IPS }}<0.50$ & $3(37 \%)$ & $5(63 \%)$ & $0(0 \%)$ \\
$0.00 \leq C_{\text {IPS }}<0.25$ & $0(0 \%)$ & $5(83 \%)$ & $1(17 \%)$ \\
Snowfall condition & $25(78 \%)$ & $1(3 \%)$ & $6(19 \%)$ \\
\hline
\end{tabular}

thermal ice thickness at the mooring site obtained from Eqs. (10), (11), and (12) for $\mathrm{PR}_{19}$ (cyan line), $\mathrm{PR}_{36}$ (yellow line), and $\mathrm{PR}_{89}$ (magenta line), respectively. These three values basically show good agreement with each other, except in the cases of thicker ice and under the snowfall condition. Since the case of thicker ice of $>0.2 \mathrm{~m}$ is beyond the scope of our thin ice thickness algorithm, it is not considered here. Meanwhile, proper handling is required for the estimation of ice thickness from the AMSR-E data under the snowfall condition. In that case, the higher-frequency channel shows larger thickness, which can be explained by the penetration depth. The $89-\mathrm{GHz}$ channel data with a smaller penetration depth is more affected by the snow on the ice surface, causing the overestimation of thermal ice thickness. It is also necessary to consider land contamination for the mapping of the ice thickness. Since the PR value at the land surface is much smaller than that at the sea ice surface, the ice thickness obtained from AMSR-E at the pixel including land is overestimated. Such land contamination has the greatest influence on the $19-\mathrm{GHz}$ channel with a larger footprint, and the least influence on the $89-\mathrm{GHz}$ channel. Therefore, for estimation of thermal ice thickness, we compare three values obtained from 19-, 36-, and 89-GHz data and adopt the thinnest. This allows us to minimize the overestimation due to snowfall and land contamination.

Next, we propose a derivation method of thin ice thickness, taking account of classification of three ice types. The $\mathrm{PR}-h_{i}$ relationship for active frazil in the Antarctic coastal polynyas was proposed by Nakata et al. (2019), based on the comparison with the ice thickness obtained from MODIS infrared images. In this study, we assumed that this relationship is commonly applicable to active frazil in any sea ice areas, and we used this to estimate the ice thickness when the pixel is classified as active frazil. On the other hand, mixed ice is difficult to handle because its PR $-h_{i}$ relationship depends on how thin solid ice and active frazil are mixed within the footprint. We introduce an ad hoc assumption that mixed ice exhibits an intermediate relationship between active frazil and thin solid ice. Namely, the thickness of mixed ice with a certain PR value is obtained as the average of the thicknesses of active frazil and thin solid ice corresponding to that PR value. The ice thickness obtained by this method is shown by black solid lines in Fig. 10 and is compared with the IPS thermal ice thickness (Fig. 10b). As shown in Fig. 10b, AMSR-E and IPS thermal ice thicknesses show good agreement with each other, even in cases of active frazil and mixed ice (indicated by red and green bars, respectively), validating the method for estimating the thickness of mixed ice, as well as that of active frazil. Figure 11 shows a scatterplot of AMSR-E and IPS thermal ice thicknesses. The root-mean-square error between the AMSR-E ice thickness and IPS thermal ice thickness excluding (including) the snowfall cases is $0.047 \mathrm{~m}(0.048 \mathrm{~m})$

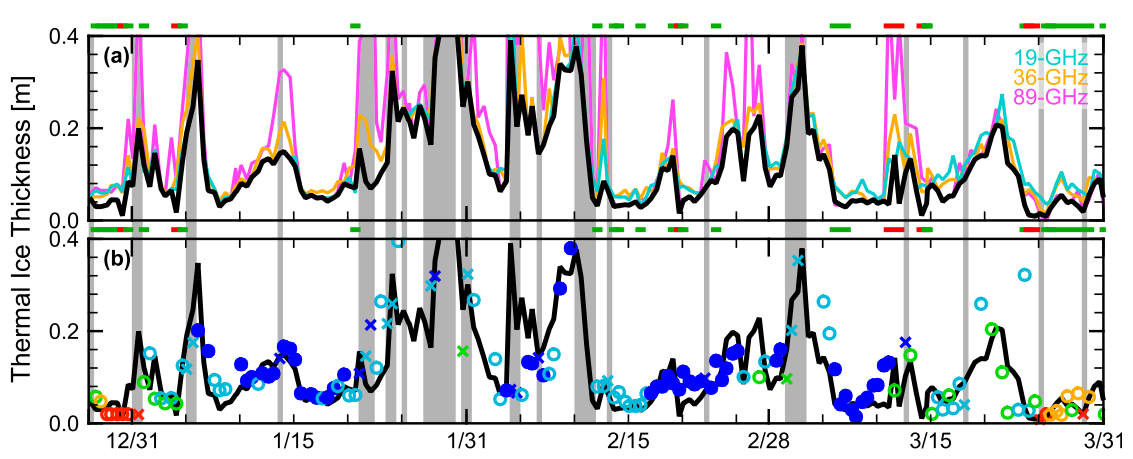

FIG. 10. Time series of sea ice thicknesses at the mooring site. Cyan, yellow, and magenta solid lines indicate the ice thicknesses obtained from $\mathrm{PR}_{19}, \mathrm{PR}_{36}$, and $\mathrm{PR}_{89}$ by using Eqs. (10), (11), and (12), respectively. The black solid line indicates the ice thickness obtained from the improved thin ice thickness algorithm considering the ice type. IPS thermal ice thickness is shown by the same symbols as those in Fig. 6. The gray shading indicates the timings of snowfall near the mooring site. Red and green bars in the top indicate the periods of active frazil and mixed ice, respectively, by the algorithm. 


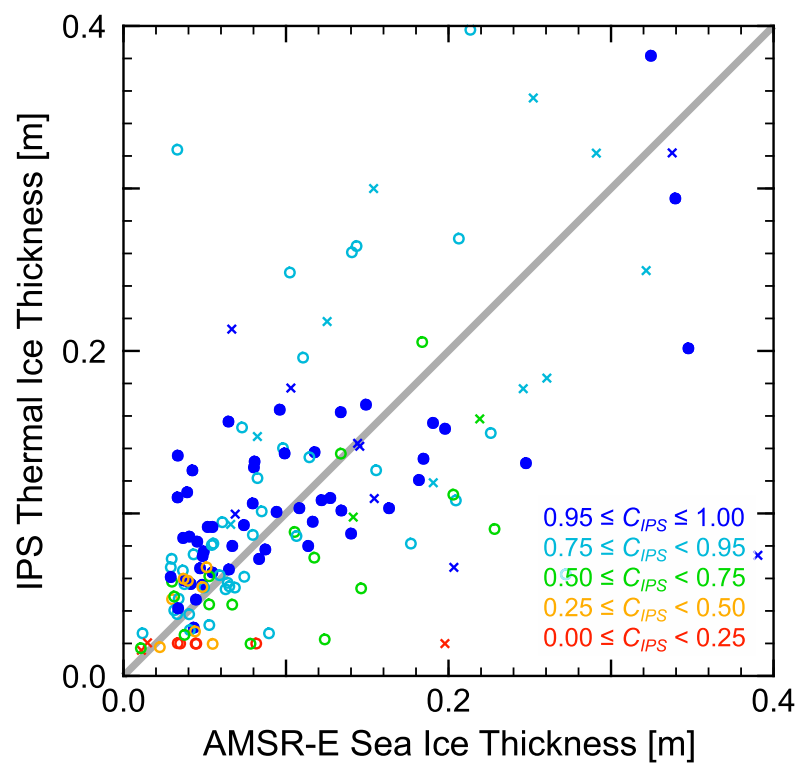

FIG. 11. Scatterplot of sea ice thickness obtained from AMSR-E data using the improved thin ice thickness algorithm vs IPS thermal ice thickness at the mooring site. Symbols and coloring are the same as those in Fig. 6.

for 81 cases ( 87 cases) in the range of $h_{t} \leq 0.1 \mathrm{~m}$, and $0.063 \mathrm{~m}(0.070 \mathrm{~m})$ for 30 cases (40 cases) in the range of $0.1 \mathrm{~m}<h_{t} \leq 0.2 \mathrm{~m}$. These results suggest that our improved algorithm is capable of estimating the thermal ice thickness with practical accuracy by introducing classification of the three ice types.

Finally, we show mapping results of ice thickness using our improved algorithm. Figures 12 and 13 show two examples, taken on 17 February 2003 and 29 December 2002, respectively. In the 17 February case, when thin solid ice is predominant (Fig. 12a), the AMSR-E ice thickness obtained from our algorithm is almost the same as that not considering the thin ice type (Figs. 12b,c), which also shows good agreement with the ice thickness obtained from MODIS data (Fig. 12d). On the other hand, in the 29 December case, the thin ice type classification shows that mixed ice is predominant in one part of the coastal polynya (Fig. 13a). Even in this case, the overestimation seen in the previous algorithm is solved by considering the thin ice type, and the obtained thickness agrees well with the MODIS ice thickness (Figs. 13b-d). Although our algorithm contains an ad hoc assumption, it provides significantly better estimates for the thermal ice thickness than previous algorithms, which consider only thin solid ice.

\section{Concluding remarks}

This paper takes on the challenge to elucidate how a satellite-based passive microwave radiometer with a footprint of several or tens of kilometers captures the nonuniform sea ice cover. To this end, we have created a pseudospatial series of sea ice thickness distribution by combining the time series of sea ice thickness with sea ice drift velocity and achieved the direct comparison between AMSR-E data and sea ice thickness distribution within the AMSR-E footprint. The pseudospatial series indicate that sea ice thickness deviates from uniformity to some extent, even in polynya areas.

The comparison between AMSR-E data and observed ice thickness distribution was carried out by two different ways. One way is to search for the best relational expression between the PR value and physical ice thickness, such that the PR value derived from that relational expression and averaged over all the segments of ice thickness data within the footprint $\left(\mathrm{PR}_{\mathrm{PRE}}\right)$, matches with the PR value observed by AMSR-E ( $\left.\mathrm{PR}_{\mathrm{OBS}}\right)$. Such a relational expression can be regarded as the local $\mathrm{PR}-h_{i}$ relationship, which is observed in an individual ice floe by the in situ observation (Hwang et al. 2007). Another way is to calculate the bulk thermal ice thickness for nonuniform sea ice cover within the AMSR-E footprint as a target physical quantity using the heat budget analysis and compare it with the observed PR value. This corresponds to the same method as that of the previous thin ice thickness algorithms. The results of these two methods show good agreement between the local and bulk PR $-h_{i}$ relationships. This can be explained by the high sensitivity of both the PR value and thermal ice thickness to the thinner portion of the nonuniform sea ice cover. The thermal ice thickness, obtainable from the PR value regardless of the uniform or nonuniform sea ice condition, is an appropriate physical quantity for the calculation of heat fluxes and accordingly sea ice production in ice-covered oceans. The present study asserts the validity of previous thin ice thickness algorithms that estimate thermal ice thickness in coastal polynya areas. On the other hand, since thermal ice thickness is not the arithmetic mean of the physical ice thickness, and the algorithm contains a certain error, it is not appropriate to calculate the volume of sea ice and its variation using thin ice thickness obtained from the algorithm.

Results shown in this paper are likewise valuable in terms of exhibiting the capabilities and limitations of the thin ice thickness algorithm for the satellite-based passive microwave radiometer. Since previous algorithms have been developed using the thermal ice thickness obtained only from nighttime and clear-sky infrared data, it was impossible to evaluate the bias due to observational timing and weather conditions. Comparison with the mooring data enables us to evaluate such biases, demonstrating that there is no significant bias 

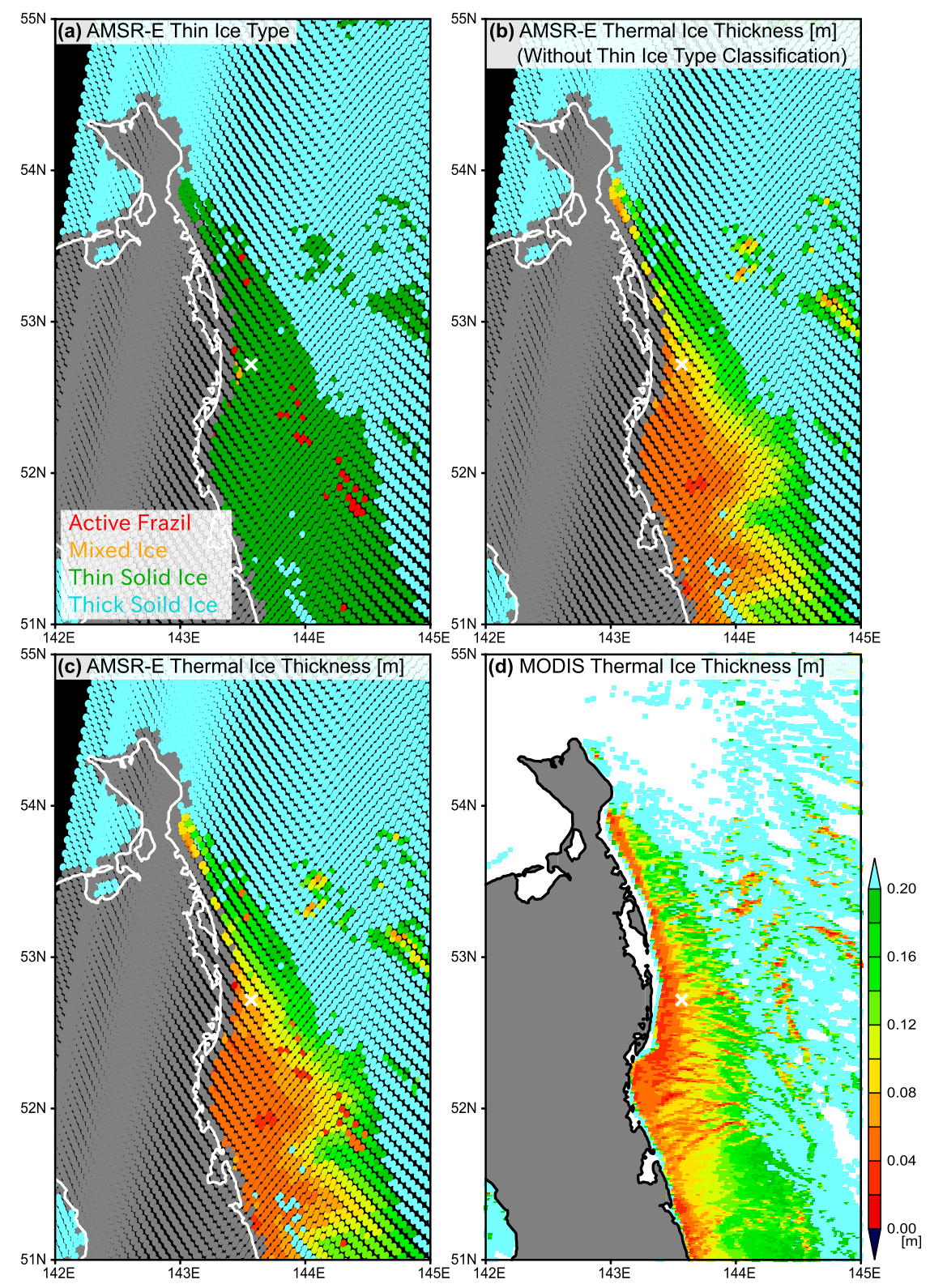

FIG. 12. Spatial distribution of (a) thin ice type classification, (b) thin ice thickness estimated without the ice type classification, (c) thin ice thickness estimated with the ice type classification, and (d) MODIS ice thickness, at 1559 UTC 17 Feb 2003. Thin ice types of active frazil, mixed ice, thin solid ice, and thick solid ice are shown by red, orange, green, and cyan in (a), respectively.

caused by observational timing in the determination of thermal ice thickness (Fig. 5). Although the bias due to weather conditions was corrected using a simple radiative transfer model (Wentz and Meissner 2000), a relatively large uncertainty still remains in the estimation of thermal ice thickness under the snowfall condition. This is likely because of the snow cover altering the characteristics of microwave radiation at the top of the ice surface.
One of the key points in improving the thin ice thickness algorithm is to classify the type of thin ice in coastal polynyas. In previous studies, a different $\mathrm{PR}-h_{i}$ relationship depending on individual oceans has been used for the thin ice thickness algorithm, implying the absence of a globally applicable algorithm. Recently, it was pointed out that such discrepancies can be explained by differences in the dominant type of thin sea ice (Nakata et al. 2019). In the case of larger $C_{\text {IPS }}$, where thin solid 

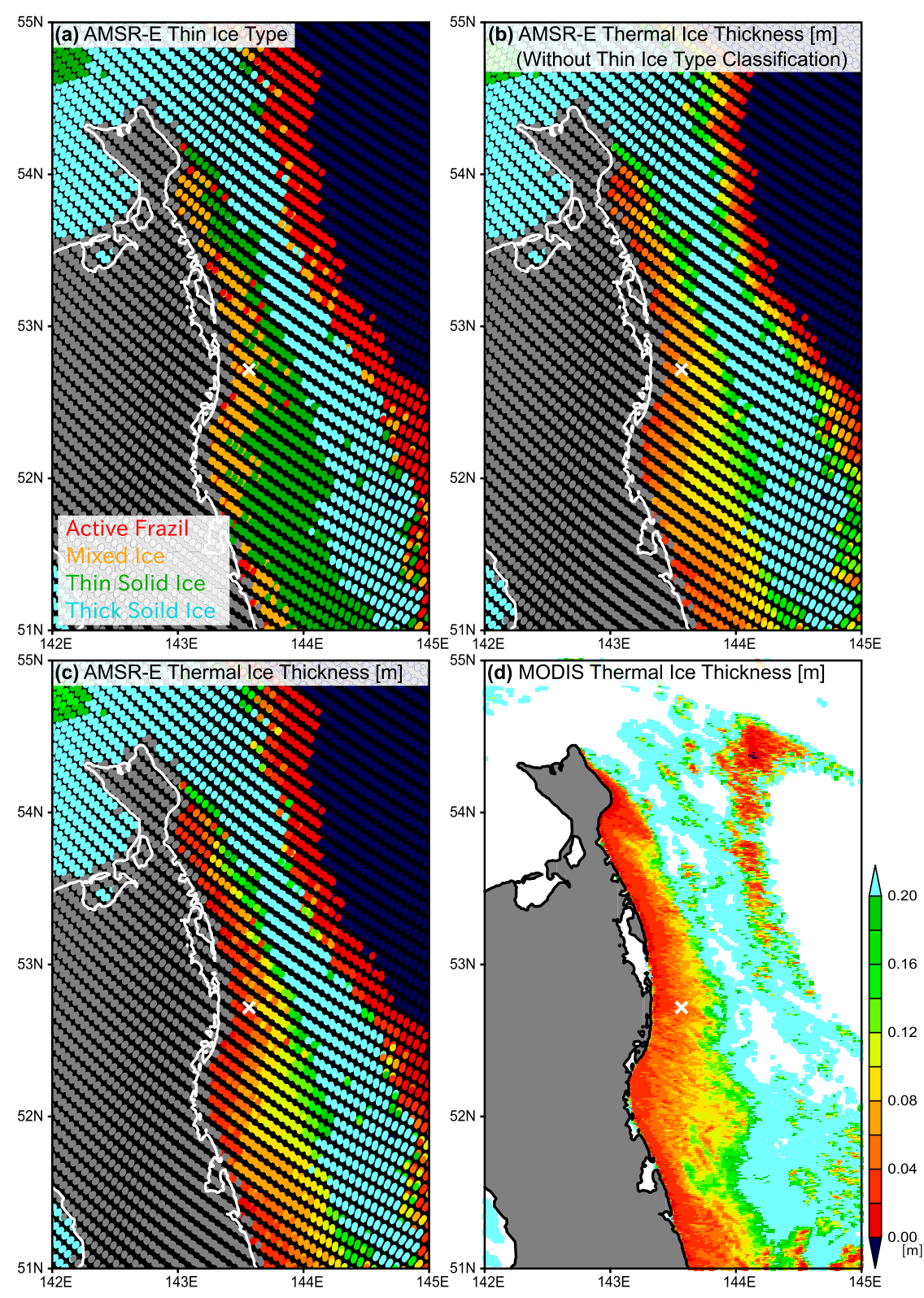

FIG. 13. Spatial distribution of (a) thin ice type classification, (b) thin ice thickness estimated without the ice type classification, (c) thin ice thickness estimated with the ice type classification, and (d) MODIS ice thickness, at 1611 UTC 29 Dec 2002. Thin ice types of active frazil, mixed ice, thin solid ice, and thick solid ice are shown by red, orange, green, and cyan in (a), respectively. The open water area (dark blue) is derived from the Enhanced NASA-Team (NT2) sea ice concentration algorithm (Markus and Cavalieri 2000).

ice may be dominant, the obtained $\mathrm{PR}-h_{i}$ relationship is very close to those obtained from the in situ observation in the Arctic Ocean (Hwang et al. 2007) and satellite-based observations in the Antarctic coastal polynya (Nihashi and Ohshima 2015; Nakata et al. 2019). In this study, we have also evaluated the algorithm for detection of active frazil (Nakata et al. 2019) using the mooring data, and then modified it to classify the polynya areas into three ice type areas of active frazil, thin solid ice, and mixed ice. Introducing such ice type classification enhances the efficacy of estimation of the thermal ice thickness even for a coastal polynya with a relatively small area of active frazil. Therefore, our improved thin ice thickness algorithm has higher versatility, which may be applicable to the global sea ice area. 
The findings of this study are expected to be applicable to the SSM/I data, at least from 1992 onward, when $85-\mathrm{GHz}$ channel data became available. Since SSM/I has a larger footprint than AMSR-E, inclusion of the mixed ice category is necessary even for a large coastal polynya. Thereby, considering the formation of frazil ice, we can describe the interannual variation and longterm trends in the polynya activity and sea ice production more accurately. This would lead to a better quantitative evaluation of heat/salt budgets and formation of DSW in polar oceans, and therefore contribute to understanding of the global climate system.

Acknowledgments. The AMSR-E data were provided by the National Snow and Ice Data Center (NSIDC), University of Colorado. This work was supported by Grants-in-Aids for Scientific Research (15403008, 17540405, 25241001, 17H01157, and 17H06317), and Arctic Research for Sustainability (ArCS) Project, from the Ministry of Education, Culture, Sports, Science and Technology in Japan. This work was also supported by a research fund for Global Change Observation Mission Water 1 (GCOM-W1) of the Japan Aerospace Exploration Agency (JAXA) (PI RA1W403 and ER2GWF404).

\section{REFERENCES}

Allison, I., R. E. Brandt, and S. G. Warren, 1993: East Antarctic sea ice: albedo, thickness distribution, and snow cover. J. Geophys. Res., 98, 12 417-12 429, https://doi.org/10.1029/93JC00648.

Andersen, S., R. T. Tonboe, S. Kern, and H. Schyberg, 2006: Improved retrieval of sea ice total concentration from spaceborne passive microwave observations using numerical weather prediction model fields: An intercomparison of nine algorithms. Remote Sens. Environ., 104, 374-392, https://doi.org/ 10.1016/j.rse.2006.05.013

Ashcroft, P., and F. J. Wentz, 2013: AMSR-E/Aqua L2A global swath spatially-resampled brightness temperatures, version 3 . Subset used: 2002-12-27 to 2003-03-31, NASA National Snow and Ice Data Center Distributed Active Archive Center, accessed 13 March 2014, https://doi.org/10.5067/AMSR-E/AE_L2A.003.

Barber, D. G., and R. A. Massom, 2007: The role of sea ice in Arctic and Antarctic polynyas. Polynyas: Windows to the World, W. O. Smith and D. G. Barber, Eds., Elsevier, 1-54, https:// doi.org/10.1016/s0422-9894(06)74001-6.

Behrendt, A., W. Dierking, E. Fahrbach, and H. Witte, 2013: Sea ice draft in the Weddell Sea, measured by upward looking sonars. Earth Syst. Sci. Data, 5, 209-226, https://doi.org/10.5194/ essd-5-209-2013.

Cavalieri, D. J., 1994: A microwave technique for mapping thin sea ice. J. Geophys. Res., 99, 12 561-12 572, https://doi.org/ 10.1029/94JC00707.

Cho, K., Y. Sato, and K. Naoki, 2016: Thin ice area extraction in the Sea of Okhotsk from GCOM-W1/AMSR2 data. Int. Arch. Photogramm. Remote Sens. Spat. Inf. Sci., XLI-8, 463-468, https://doi.org/10.5194/isprs-archives-XLI-B8-463-2016.

Cox, G. F. N., and W. F. Weeks, 1974: Salinity variations in sea ice. J. Glaciol., 13, 109-120, https://doi.org/10.1017/S0022143000023418.
Dee, D. P., and Coauthors, 2011: The ERA-Interim reanalysis: Configuration and performance of the data assimilation system. Quart. J. Roy. Meteor. Soc., 137, 553-597, https://doi.org/ 10.1002/qj.828.

Drucker, R., S. Martin, and R. Moritz, 2003: Observations of ice thickness and frazil ice in the St. Lawrence Island polynya from satellite imagery, upward looking sonar, and salinity/ temperature moorings. J. Geophys. Res., 108, 3149, https:// doi.org/10.1029/2001JC001213.

Fukamachi, Y., G. Mizuta, K. I. Ohshima, H. Melling, D. Fissel, and M. Wakatsuchi, 2003: Variability of sea-ice draft off Hokkaido in the Sea of Okhotsk revealed by a moored iceprofiling sonar in winter of 1999. Geophys. Res. Lett., 30, 1376, https://doi.org/10.1029/2002GL016197.

_ _ _ _ - T. Toyota, N. Kimura, and M. Wakatsuchi, 2006: Sea ice thickness in the southwestern Sea of Okhotsk revealed by a moored ice-profiling sonar. J. Geophys. Res., 111, C09018, https://doi.org/10.1029/2005JC003327.

, and Coauthors, 2009: Direct observations of sea-ice thickness and brine rejection off Sakhalin in the Sea of Okhotsk. Cont. Shelf Res., 29, 1541-1548, https://doi.org/10.1016/j.csr.2009.04.005.

, D. Simizu, K. I. Ohshima, H. Eicken, A. R. Mahoney, K. Iwamoto, E. Moriya, and S. Nihashi, 2017: Sea-ice thickness in the coastal northeastern Chukchi Sea from moored iceprofiling sonar. J. Glaciol., 63, 888-898, https://doi.org/10.1017/ jog.2017.56.

Grenfell, T., and J. Comiso, 1986: Multifrequency passive microwave observations of first-year sea ice grown in a Tank. IEEE Trans. Geosci. Remote Sens., GE-24, 826-831, https://doi.org/ 10.1109/TGRS.1986.289696.

Hunewinkel, T., T. Markus, and G. Heygster, 1998: Improved determination of the sea ice edge with SSM/I data for small-scale analyses. IEEE Trans. Geosci. Remote Sens., 36, 1795-1808, https://doi.org/10.1109/36.718647.

Huntemann, M., G. Heygster, L. Kaleschke, T. Krumpen, M. Mäkynen, and M. Drusch, 2014: Empirical sea ice thickness retrieval during the freeze-up period from SMOS high incident angle observations. Cryosphere, 8, 439-451, https:// doi.org/10.5194/tc-8-439-2014.

Hwang, B. J., J. K. Ehn, D. G. Barber, R. Galley, and T. C. Grenfell, 2007: Investigations of newly formed sea ice in the Cape Bathurst polynya: 2. Microwave emission. J. Geophys. Res., 112, C05003, https://doi.org/10.1029/2006JC003703.

Ivanova, N., and Coauthors, 2015: Inter-comparison and evaluation of sea ice algorithms: towards further identification of challenges and optimal approach using passive microwave observations. Cryosphere, 9, 1797-1817, https://doi.org/ 10.5194/tc-9-1797-2015.

Iwamoto, K., K. I. Ohshima, T. Tamura, and S. Nihashi, 2013: Estimation of thin ice thickness from AMSR-E Data in the Chukchi Sea. Int. J. Remote Sens., 34, 468-489, https://doi.org/ 10.1080/01431161.2012.712229.

- $—$, and,- 2014 : Improved mapping of sea ice production in the Arctic Ocean using AMSR-E thin ice thickness algorithm. J. Geophys. Res. Oceans, 119, 3574-3594, https:// doi.org/10.1002/2013JC009749.

Kashiwase, H., K. I. Ohshima, and S. Nihashi, 2014: Long-term variation in sea ice production and its relation to the intermediate water in the Sea of Okhotsk. Prog. Oceanogr., 126, 21-32, https://doi.org/10.1016/j.pocean.2014.05.004.

Kim, Y.-S., and R. Kimura, 1995: Error evaluation of the bulk aerodynamic method for estimating heat flux over the sea. J. Korean Meteor. Soc., 31, 399-413. 
Kimura, N., and M. Wakatsuchi, 1999: Processes controlling the advance and retreat of sea ice in the Sea of Okhotsk. J. Geophys. Res., 104, 11137-11150, https://doi.org/10.1029/ 1999JC900004.

Kondo, J., 1975: Air-sea bulk transfer coefficients in diabatic conditions. Bound.-Layer Meteor., 9, https://doi.org/10.1007/ BF00232256.

Markus, T., and D. J. Cavalieri, 2000: An enhancement of the NASA Team sea ice algorithm. IEEE Trans. Geosci. Remote Sens., 38, 1387-1398, https://doi.org/10.1109/36.843033.

_, and - 2009: The AMSR-E NT2 sea ice concentration algorithm: Its basis and implementation. J. Remote Sens. Soc. Japan, 29, 216-225, https://doi.org/10.11440/rssj.29.216.

Martin, S., R. Drucker, and K. Yamashita, 1998: The production of ice and dense shelf water in the Okhotsk Sea polynyas. J. Geophys. Res., 103, 27 771-27 782, https://doi.org/10.1029/ 98JC02242.

R. Kwok, and B. Holt, 2004: Estimation of the thin ice thickness and heat flux for the Chukchi Sea Alaskan coast polynya from Special Sensor Microwave/Imager data, 19902001. J. Geophys. Res., 109, C10012, https://doi.org/10.1029/ 2004JC002428.

$\ldots, \ldots, \ldots$, and $\_, 2005$ : Improvements in the estimates of ice thickness and production in the Chukchi Sea polynyas derived from AMSR-E. Geophys. Res. Lett., 32, L05505, https:// doi.org/10.1029/2005GL023800.

Mathew, N., G. Heygster, and C. Melsheimer, 2009: Surface emissivity of the Arctic sea ice at AMSR-E frequencies. IEEE Trans. Geosci. Remote Sens., 47, 4115-4124, https://doi.org/ 10.1109/TGRS.2009.2023667.

Mätzler, C., 1992: Ground-based observations of atmospheric radiation at 5, 10, 21, 35, and $94 \mathrm{GHz}$. Radio Sci., 27, 403-415, https://doi.org/10.1029/91RS03052.

Maykut, G. A., 1978: Energy exchange over young sea ice in the central Arctic. J. Geophys. Res., 83, 3646-3658, https://doi.org/ 10.1029/JC083iC07p03646.

- 1986: The surface heat and mass balance. The Geophysics of Sea Ice, N. Untersteiner, Ed., Plenum, 395-463.

Melling, H., and D. A. Riedel, 1995: The underside topography of sea ice over the continental shelf of the Beaufort Sea in the winter of 1990. J. Geophys. Res., 100, 13 641-13 653, https:// doi.org/10.1029/95JC00309.

_ , and —_, 1996: Development of seasonal pack ice in the Beaufort Sea during the winter of 1991-1992: A view from below. J. Geophys. Res., 101, 11 975-11 991, https://doi.org/ 10.1029/96JC00284.

— - P. H. Johnston, and D. A. Riedel, 1995: Measurements of the underside topography of sea ice by moored subsea sonar. J. Atmos. Oceanic Technol., 12, 589-602, https://doi.org/10.1175/ 1520-0426(1995)012<0589:MOTUTO>2.0.CO;2.

Mizuta, G., Y. Fukamachi, K. I. Ohshima, and M. Wakatsuchi, 2003: Structure and seasonal variability of the East Sakhalin Current. J. Phys. Oceanogr., 33, 2430-2445, https://doi.org/ 10.1175/1520-0485(2003)033<2430:SASVOT $>2.0 . C O ; 2$.

Morales Maqueda, M. A., A. J. Willmott, and N. R. T. Biggs, 2004: Polynya dynamics: A review of observations and modeling. Rev. Geophys., 42, RG1004, https://doi.org/10.1029/ 2002RG000116.

Nakanowatari, T., K. I. Ohshima, and M. Wakatsuchi, 2007: Warming and oxygen decrease of intermediate water in the northwestern North Pacific, originating from the Sea of Okhotsk, 1955-2004. Geophys. Res. Lett., 34, L04602, https://doi.org/ 10.1029/2006GL028243.
Nakata, K., K. I. Ohshima, and S. Nihashi, 2019: Estimation of thinice thickness and discrimination of ice type from AMSR-E passive microwave data. IEEE Trans. Geosci. Remote Sens., 57, 263-276, https://doi.org/10.1109/TGRS.2018.2853590.

Nihashi, S., and K. I. Ohshima, 2015: Circumpolar mapping of antarctic coastal polynyas and landfast sea ice: Relationship and variability. J. Climate, 28, 3650-3670, https://doi.org/10.1175/ JCLI-D-14-00369.1.

,$- \ldots$, T. Tamura, Y. Fukamachi, and S. Saitoh, 2009: Thickness and production of sea ice in the Okhotsk Sea coastal polynyas from AMSR-E. J. Geophys. Res., 114, C10025, https:// doi.org/10.1029/2008JC005222.

,-- , and 2017: Sea-ice production in Antarctic coastal polynyas estimated from AMSR2 data and its validation using AMSR-E and SSM/I-SSMIS data. IEEE J. Sel. Top. Appl. Earth Obs. Remote Sens., 10, 3912-3922, https://doi.org/ 10.1109/JSTARS.2017.2731995.

Ohshima, K. I., T. Watanabe, and S. Nihashi, 2003: Surface heat budget of the Sea of Okhotsk during 1987-2001 and the role of sea ice on it. J. Meteor. Soc. Japan, 81, 653-677, https://doi.org/ 10.2151/jmsj.81.653.

_ - S. Nihashi, and K. Iwamoto, 2016: Global view of sea-ice production in polynyas and its linkage to dense/bottom water formation. Geosci. Lett., 3, 13, https://doi.org/10.1186/s40562016-0045-4.

Orsi, A. H., G. C. Johnson, and J. L. Bullister, 1999: Circulation, mixing and production of Antarctic Bottom Water. Prog. Oceanogr., 43, 55-109, https://doi.org/10.1016/S00796611(99)00004-X.

Paul, S., S. Willmes, and G. Heinemann, 2015: Long-term coastalpolynya dynamics in the southern Weddell Sea from MODIS thermal-infrared imagery. Cryosphere, 9, 2027-2041, https:// doi.org/10.5194/tc-9-2027-2015.

Poe, G. A., 1990: Optimum interpolation of imaging microwave radiometer data. IEEE Trans. Geosci. Remote Sens., 28, 800810, https://doi.org/10.1109/36.58966.

Preußer, A., G. Heinemann, S. Willmes, and S. Paul, 2016: Circumpolar polynya regions and ice production in the Arctic: Results from MODIS thermal infrared imagery from $2002 / 2003$ to $2014 / 2015$ with a regional focus on the Laptev Sea. Cryosphere, 10, 3021-3042, https://doi.org/10.5194/ tc-10-3021-2016.

Purkey, S. G., and G. C. Johnson, 2012: Global contraction of Antarctic Bottom Water between the 1980s and 2000. J. Climate, 25, 5830-5844, https://doi.org/10.1175/JCLI-D11-00612.1.

Shcherbina, A. Y., L. D. Talley, and D. L. Rudnick, 2003: Direct observations of North Pacific ventilation: brine rejection in the Okhotsk Sea. Science, 302, 1952-1955, https://doi.org/ 10.1126/science. 1088692.

Shokr, M., K. Asmus, and T. Agnew, 2009: Microwave emission observations from artificial thin sea ice: The ice-tank experiment. IEEE Trans. Geosci. Remote Sens., 47, 325-338, https:// doi.org/10.1109/TGRS.2008.2005585.

Steffen, K., 1991: Energy flux density estimation over sea ice based on satellite passive microwave measurements. Ann. Glaciol., 15, 178-183, https://doi.org/10.3189/1991AoG151-178-183.

- and J. A. Maslanik, 1988: Comparison of Nimbus 7 Scanning Multichannel Microwave Radiometer radiances and derived sea ice concentrations with Landsat imagery for the North Water area of Baffin Bay. J. Geophys. Res., 93, 10 769-10 781, https://doi.org/10.1029/JC093iC09p10769. 
Strass, V. H., 1998: Measuring sea ice draft and coverage with moored upward looking sonars. Deep-Sea Res. I, 45, 795-818, https://doi.org/10.1016/S0967-0637(97)00065-4.

Tamura, T., and K. I. Ohshima, 2011: Mapping of sea ice production in the Arctic coastal polynyas. J. Geophys. Res., 116, C07030, https://doi.org/10.1029/2010JC006586.

, — - T. Markus, D. J. Cavalieri, S. Nihashi, and N. Hirasawa, 2007: Estimation of thin ice thickness and detection of fast ice from SSM/I data in the Antarctic Ocean. J. Atmos. Oceanic Technol., 24, 1757-1772, https://doi.org/10.1175/JTECH2113.1. , and S. Nihashi, 2008: Mapping of sea ice production for Antarctic coastal polynyas. Geophys. Res. Lett., 35, L07606, https://doi.org/10.1029/2007GL032903.

, — , A. D. Fraser, and G. D. Williams, 2016: Sea ice production variability in Antarctic coastal polynyas. J. Geophys. Res. Oceans, 121, 2967-2979, https://doi.org/10.1002/2015JC011537.

Tian-Kunze, X., L. Kaleschke, N. Maaß, M. Mäkynen, N. Serra, M. Drusch, and T. Krumpen, 2014: SMOS-derived thin sea ice thickness: Algorithm baseline, product specifications and initial verification. Cryosphere, 8, 997-1018, https://doi.org/ 10.5194/tc-8-997-2014.

Toyota, T., J. Ukita, K. I. Ohshima, M. Wakatsuchi, and K. Muramoto, 1999: A measurement of sea ice albedo over the southwestern Okhotsk Sea. J. Meteor. Soc. Japan, 77, 117-133, https:// doi.org/10.2151/jmsj1965.77.1_117.

Warner, M. J., J. L. Bullister, D. P. Wisegarver, R. H. Gammon, and R. F. Weiss, 1996: Basin-wide distributions of chlorofluorocarbons CFC-11 and CFC-12 in the North Pacific: 1985-1989. J. Geophys. Res., 101, 20 525-20 542, https://doi.org/ 10.1029/96JC01849.

Wentz, F. J., 1997: A well-calibrated ocean algorithm for special sensor microwave / imager. J. Geophys. Res., 102, 8703-8718, https://doi.org/10.1029/96JC01751.

, and T. Meissner, 2000: AMSR ocean algorithm, version 2. Tech. Proposal 121599A-1, NASA GSFC, 66 pp.

Yu, Y., and D. A. Rothrock, 1996: Thin ice thickness from satellite thermal imagery. J. Geophys. Res., 101, 25 753-25 766, https:// doi.org/10.1029/96JC02242. 